\title{
Integrated assessment of biomass supply and demand in climate change mitigation scenarios
}

\author{
Vassilis Daioglou ${ }^{\mathrm{a}, \mathrm{b}, *}$, Jonathan C. Doelman ${ }^{\mathrm{a}}$, Birka Wicke ${ }^{\mathrm{b}}$, Andre Faaij ${ }^{\mathrm{c}}$, Detlef P. van Vuuren ${ }^{\mathrm{a}, \mathrm{b}}$ \\ ${ }^{a}$ PBL Netherlands Environmental Assessment Agency, PO Box 30314, 2500 GH, The Hague, the Netherlands \\ ${ }^{\mathrm{b}}$ Copernicus Institute of Sustainable Development, Utrecht University, Princetonlaan 8a, 3584 CB, Utrecht, the Netherlands \\ ${ }^{\mathrm{c}}$ Energy Sustainability Research Institute Groningen (ESRIG), University of Groningen, Blauwborgje 6, PO Box 221, 9700 AE, Groningen, the Netherlands
}

\section{A R T I C L E I N F O}

\section{Keywords:}

Bioenergy

Scenario analysis

Climate policy

Land use

Energy system

Biochemicals

\begin{abstract}
A B S T R A C T
Biomass is often seen as a key component of future energy systems as it can be used for heat and electricity production, as a transport fuel, and a feedstock for chemicals. Furthermore, it can be used in combination with carbon capture and storage to provide so-called "negative emissions". At the same time, however, its production will require land, possibly impacting food security, land-based carbon stocks, and other environmental services. Thus, the strategies adopted in the supply, conversion, and use of biomass have a significant impact on its effectiveness as a climate change mitigation measure. We use the IMAGE 3.0 integrated assessment model to project three different global, long term scenarios spanning different socioeconomic futures with varying rates of population growth, economic growth, and technological change, and investigate the role of biomass in meeting strict climate targets. Using these scenarios we highlight different possibilities for biomass supply and demand, and provide insights on the requirements and challenges for the effective use of this resource as a climate change mitigation measure. The results show that in scenarios meeting the $1.5{ }^{\circ} \mathrm{C}$ target, biomass could exceed $20 \%$ of final energy consumption, or $115-180 \mathrm{EJ}_{\mathrm{Prim}} / \mathrm{yr}$ in 2050 . Such a supply of bioenergy can only be achieved without extreme levels land use change if agricultural yields improve significantly and effective land zoning is implemented. Furthermore, the results highlight that strict mitigation targets are contingent on the availability of advanced technologies such as lignocellulosic fuels and carbon capture and storage.
\end{abstract}

\section{Introduction}

Biomass is projected to be an important component of future energy systems aiming to meet strict climate targets (Clarke et al., 2014; Rose et al., 2014; Rogelj et al., 2018). From a policy perspective, the use of bioenergy can be an attractive option to reduce greenhouse gas (GHG) emissions and to improve energy security. Still, several problems exist with large-scale bioenergy use, including competition with other forms of land use and (in)direct greenhouse gas emissions (Searchinger et al., 2008; Daioglou et al., 2017). Also, it is unclear how the overall reduction of GHGs varies across different biomass supply possibilities and end-uses. Thus, the role of biomass in mitigation efforts depends on the entire supply chain, including factors such as land use dynamics, the volume and type of replaced fossil fuels and potential feedbacks in the energy system. This means that when setting up policies to mitigate climate change through the use of biomass, bioenergy, and biochemicals, it is important to understand the interactions and tradeoffs within and between the energy and land systems (Dornburg et al., 2010;
Hoogwijk et al., 2005; Slade et al., 2014; Smeets et al., 2007; Doelman et al., 2018).

The global and long-term development of these systems, and their interactions, are influenced by a large number of uncertainties. These include population dynamics, economic development, demand for food, fodder, fiber and energy services, changes in production intensity of agriculture and forestry, decisions concerning land conservation, and the availability and costs of advanced energy conversion technologies. Scenario analyses can illustrate plausible and consistent possibilities for how these uncertainties may unfold (Nakicenovic et al., 2000). The resultant broad set of potential outcomes can then provide insights into the possibilities, requirements, ranges, and sensitivities of bioenergy supply and demand (Clarke et al., 2014; Kriegler et al., 2012; Riahi et al., 2017). Previous scenario studies have highlighted the potential role of biomass and bioenergy in climate mitigation strategies of the energy system and have investigated the sensitivity of these strategies on fossil fuel prices, and the availability of biomass and different advanced technologies (Rose et al., 2014; Bauer et al., 2018; Calvin et al.,

\footnotetext{
* Corresponding author at: PBL Netherlands Environmental Assessment Agency, PO Box 30314, 2500, The Hague, the Netherlands.

E-mail address: vassilis.daioglou@pbl.nl (V. Daioglou).
} 
2016), however they have not addressed the uncertainties on the supply side.

Popp et al. (2017) and Bauer et al. (2017) have used the Shared Socioeconomic Pathways (SSP) scenario framework to explore potential futures for the land and energy systems, respectively. However, as these studies present results from multiple models and for the entire energy and land systems, they do not provide clear insights concerning the dynamics of biomass supply and demand and the sensitivities of its efficacy as a climate change mitigation measure. In this paper we aim to explore the sensitivities, synergies, and tradeoffs of biomass as a climate change mitigation option in a consistent and integrated manner by assessing different biomass supply and demand futures, and the associated GHG emissions. We use the global long term (2100) projections of the SSP scenarios according to the IMAGE 3.0 model (Doelman et al., 2018; Stehfest et al., 2014; van Vuuren et al., 2017) to build upon and go beyond previous literature by focusing on biomass pathways within the broader energy and land system contexts. IMAGE 3.0 is an Integrated Assessment Model (IAM) which projects the global and long term interactions of the land-use, agricultural, energy, and climate systems. The analysis aims to bring forward the dynamics which may lead to different biomass supply and demand pathways, highlighting the key issues which affect the climate change mitigation efficacy of biomass and bioenergy.

In Section 2, the main model and scenario assumptions are outlined. Section 3 presents the land use and energy system projections of the baseline and mitigation scenarios. Following it presents details of the scenario projections concerning biomass supply and demand, highlighting synergies and tradeoffs pertinent for climate change mitigation strategies. Section 4 discusses key issues concerning the use of biomass, and, finally, Section 5 draws conclusions, policy recommendations, and proposes future research avenues.

\section{Method}

This study is based on projections of the IMAGE 3.0 model, which integrates the interactions between the land-use, agricultural, energy, and climate systems. The following sections outline some important aspects of the method adopted in this paper. Further details and references on the scenario description, and how the IMAGE 3.0 model determines the supply and demand of biomass, and its effect on energy and land-use emissions, are available in the Appendix.

\subsection{Scope and definitions}

All results are presented for a global and long-term basis. Throughout this paper, biomass is defined as the primary resource for bio-based energy and non-energy (biochemical) applications. Unless otherwise stated, the term is used interchangeably for lignocellulosic, sugar and starch crops, as well as agricultural and forestry residues. Bioenergy consists of secondary energy carriers and final energy uses supplied from biomass such as solids (for heat production in buildings and industry), liquids (biofuels used in transport), electricity, and hydrogen. In this definition we exclude low quality traditional uses such as heating or cooking in poor households.

GHG emissions are presented for energy supply, energy demand, agriculture, and land use change (LUC). Energy supply includes emissions from energy supply chains (including fertilizer use for biomass production) and conversion to secondary energy carriers. Energy demand emissions are due to combustion at final use. LUC emissions are changes in carbon-stocks due to changes in land cover (deforestation, abandonment, etc.). $\mathrm{CH}_{4}$ and $\mathrm{N}_{2} \mathrm{O}$ emissions from land (including rice cultivation, animal waste management etc.) and energy use are presented separately, converted to $\mathrm{CO}_{2}$-equivalents $\left(\mathrm{CO}_{2}\right.$-eq).

\subsection{Biomass and its energy and non-energy applications in IMAGE 3.0}

In IMAGE 3.0 primary biomass can be produced on abandoned agricultural lands or other natural lands (grasslands, shrubland, savannah, tundra), or supplied by residues (Hoogwijk et al., 2009, 2003; Daioglou et al., 2016). This method explicitly assumes a "food-first" principle, where biomass supply cannot directly displace agricultural production for food. Additionally, biomass production is excluded from areas of high environmental value such as forests (for more details see the Appendix). Potential energy crops are sugarcane, maize, and lignocellulosic crops which consist of perennial grasses (miscanthus) and woody crops (willow and eucalyptus). Biomass supply from residues is based on production volumes and intensity in agriculture and forestry. The supply is limited by environmental factors and competing demand options such as livestock feed and traditional fuel use in poor households. Supply costs for both energy crops and residues are based on capital, labour, transport costs, and the intensity of production.

The energy system is represented in IMAGE 3.0 by the TIMER dynamic simulation model (van Vuuren et al., 2007). This model assumes primary biomass can be converted to a number of secondary and final energy carriers: solid fuel, liquid fuel, electricity and hydrogen. Both first and second generation liquid fuels are included. Potential electricity production routes include steam turbine, combined cycle, combined heat and power, and combinations with carbon capture and storage (CCS). Hydrogen production is based on gasification and can be combined with CCS. It is important to note that in IMAGE 3.0 there is no representation of liquid biofuels with CCS. Besides energy carriers, biomass can also be converted into a feedstock for chemical production, competing with petrochemicals (Daioglou et al., 2014). The model projects energy demand for different end-use sectors (industry, feedstocks, transport, residential, services and "other"). Biomass-based energy carriers and chemicals compete with other secondary and final energy carriers (including fossil fuels and other renewables) in order to supply this demand. The final market shares of different energy carriers are based on their relative costs. The Appendix provides further details on how IMAGE 3.0 projects the supply and demand of biomass, and the associated effects on GHG emissions.

\subsection{Scenario description}

The model is used to project three different reference baselines. These are scenarios with varying socio-economic futures and assume no action on climate change. Following, we also project different mitigation scenarios for each baseline, where a given climate target is achieved through the application of climate policy. The scenario framework is based on the Shared Socioeconomic Pathways (SSPs) which describe plausible alternative trends in the evolution of society over a century timescale (Riahi et al., 2017; O'Neill et al., 2017). These pathways explore the different socioeconomic development possibilities, characterized by their challenges to climate mitigation and adaptation (see description below), which lead to varying land and energy use, and resultant GHG emissions. Here we compare and contrast the results of SSP1, SSP2, and SSP3. These scenarios span a range of possible technoeconomic and land use futures relevant for the supply and demand of biomass. Below we describe the main qualitative elements of the baselines and how they are applied in IMAGE 3.0. Relevant technological and socioeconomic indicators for each baseline are shown in Tables A2, A3 and A4 in the Appendix. Further details about the implementation of the SSPs scenarios in IMAGE 3.0, as well as quantitative results for energy and land use can be found in van Vuuren et al. (2017) and Doelman et al. (2018).

The SSP1 baseline describes a world with low challenges to adaptation and mitigation. Population reaches a maximum by mid-century, decreasing thereafter, while global GDP per capita increases significantly. There are efforts to conserve biodiversity, and behavioral 
changes lead to diets with a reduced demand for meat as well as fewer energy services. Meanwhile, there are sustained improvements in crop and livestock yields, and investments in research and development allow for significant improvements in efficiency and costs of energy technologies and a reduction in energy intensity. SSP2 assumes a middle of the road development, based on the extrapolation of current trends. Population continues to increase, stabilizing towards the end of the century. Some efforts are made to conserve natural lands and there are moderate improvements in agricultural production and energy technologies and intensity. SSP3 projects a world with high challenges to both adaptation and mitigation. It assumes a regionalized world with very high population growth and only small increases in GDP per capita. Behavioral choices follow an inefficient use of mostly fossil based energy carriers while diets increasingly shift towards meat consumption. This baseline assumes that there is fragmentation between regions, few restrictions on land use and expansion, and only minor improvements in technologies and energy efficiency take place.

Mitigation scenarios are projected by simulating the application of climate policies through the adoption of global carbon taxes in order to meet the radiative forcing targets consistent with $1.5^{\circ} \mathrm{C}$ and $2{ }^{\circ} \mathrm{C}$ global mean temperature change. These carbon taxes are endogenously determined and their application promotes the adoption of low-greenhouse gas technologies and improvements in efficiency. Furthermore, as shown in Table 1, stricter constraints on land availability are exogenously placed, restricting agriculture and bioenergy expansion on lands with high carbon stocks (Doelman et al., 2018). Non-CO 2 GHGs from energy, land and agricultural sources are also curtailed through the application of the carbon tax through the use of marginal abatement cost curves (Lucas et al., 2007). Projections of climate indicators (radiative forcing and mean global temperature change) and carbon taxes across all scenarios are available in the Appendix (Figure A2).

Long term radiative forcing targets are used to define the mitigation scenarios. The $2.6 \mathrm{~W} / \mathrm{m}^{2}$ and $1.9 \mathrm{~W} / \mathrm{m}^{2}$ targets have a $66 \%$ likelihood of meeting a $2{ }^{\circ} \mathrm{C}$ and $1.5^{\circ} \mathrm{C}$ mean global temperature change targets respectively by 2100 (Collins et al., 2013; van Vuuren et al., 2011). Since the socio-economic and technological storyline of the SSP3 baseline makes strict climate goals infeasible, the SSP3 baseline only has one mitigation scenario, with a radiative forcing target of $3.4 \mathrm{~W} / \mathrm{m}^{2}$, implying a low $\left(<50 \%\right.$ ) likelihood to meet to $2^{\circ} \mathrm{C}$ target. The inability of this baseline to meet strict mitigation targets is also reflected in other IAMs (Fujimori et al., 2017).

\section{Results}

\subsection{Land use and energy system projections}

Different SSP storylines (and their mitigation scenarios) lead to different land use and the energy system futures. These in turn affect the future availability of biomass, its energy and non-energy applications, and their emission mitigation possibilities. Below we outline some of the land use and energy trends in order to put the results in Section 3.2 into context. Further details and quantitative results for energy and land use can be found in van Vuuren et al. (2017) and Doelman et al. (2018).

\subsubsection{Land use trends}

Population and welfare growth in all three baselines lead to an increase in the demand for crop and livestock production (see Table A4 in the Appendix). These increases, combined with changes in production intensity, lead to the different land use projections (Fig. 1). In 2010, land use for food crops and pasture was approximately $4800 \mathrm{MHa}$ (FAO, 2013). The SSP1 scenarios has the lowest overall demand for crop and livestock production and combined with a strong increase in production intensity, this leads to a net abandonment of agricultural lands and an increase in forest cover and other natural lands. Thus in the SSP1 scenario, land use for food crops and pasture decreases by 300 MHa by 2050, and by almost $700 \mathrm{MHa}$ in 2100 . A portion of abandoned and other natural lands are, in principle, available for biomass production (see Section 2.2 and Table A1 in the Appendix). SSP3 forms the other extreme. Here, increases in global population lead to a growing demand for agriculture and pasture, while limited improvements in yields drives land use to increase by over 800 MHa by 2050. By 2100, total land use for food production in the SSP3 baseline stands at approximately $5800 \mathrm{MHa}$, putting further pressure on forests and other natural lands.

As shown in Fig. 1, forests and other natural lands account for approximately $62 \%$ of land cover in 2010 . For SSP1, the trends discussed above lead to a small increase to $63 \%$ by the end of the century. Conversely, for SSP2 and SSP3 there is a continuing loss of natural lands whose coverage decreases to $57 \%$ and $53 \%$ of land cover respectively in 2100 .

Table 1

Outline of scenarios presented in this paper, and their most important characteristics concerning biomass supply and demand. Further details are available in the appendix.

\begin{tabular}{|c|c|c|c|}
\hline & SSP1 & SSP2 & SSP3 \\
\hline \multirow[t]{2}{*}{ Baseline } & $\begin{array}{l}\text { High technological development and } \\
\text { agricultural yields; Preference for clean } \\
\text { technologies and low meat diets; Globalized } \\
\text { world }\end{array}$ & $\begin{array}{l}\text { Moderate technological development and yield } \\
\text { improvement }\end{array}$ & $\begin{array}{l}\text { Low technological development and yield } \\
\text { improvement; Regionalized world }\end{array}$ \\
\hline & \multicolumn{3}{|c|}{ Additional characteristics for the mitigation scenarios } \\
\hline $\begin{array}{l}\text { Mitigation - } \\
\quad 3.4 \mathrm{~W} / \mathrm{m}^{2}\end{array}$ & - & - & $\begin{array}{l}\text { No efforts towards reforestation or protection } \\
\text { of land based carbon stocks; Mitigation comes } \\
\text { primarily from the energy sector }\end{array}$ \\
\hline $\begin{array}{l}\text { Mitigation - } \\
2.6 \mathrm{~W} / \mathrm{m}^{2}\end{array}$ & $\begin{array}{l}\text { High efforts towards reforestation; Protection } \\
\text { of high carbon stock areas }\end{array}$ & $\begin{array}{l}\text { Moderate efforts towards reforestation; Protection of } \\
\text { moderate carbon stock areas }\end{array}$ & $\begin{array}{l}\text { No efforts towards reforestation or protection } \\
\text { of land based carbon stocks; Mitigation comes } \\
\text { primarily from the energy sector }\end{array}$ \\
\hline $\begin{array}{l}\text { Mitigation - } \\
\quad 1.9 \mathrm{~W} / \mathrm{m}^{2}\end{array}$ & $\begin{array}{l}\text { High efforts towards reforestation; Protection } \\
\text { of high carbon stock areas }\end{array}$ & $\begin{array}{l}\text { High efforts towards reforestation; Protection of high } \\
\text { carbon stock areas; Increased biomass accessibility factors } \\
\text { for non-forest lands; Some biomass production in boreal } \\
\text { forests while ensuring long term maintenance of carbon } \\
\text { stocks }{ }^{1}\end{array}$ & Not feasible \\
\hline
\end{tabular}

\footnotetext{
1 This scenario requires high volumes of biomass in order to meet the climate target. In order to increase biomass availability, direct deforestation in some boreal

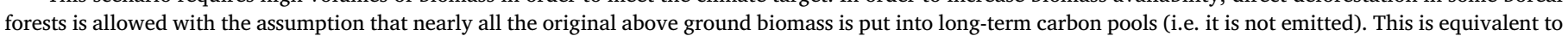
assuming that it is used for bioenergy purposes.
} 

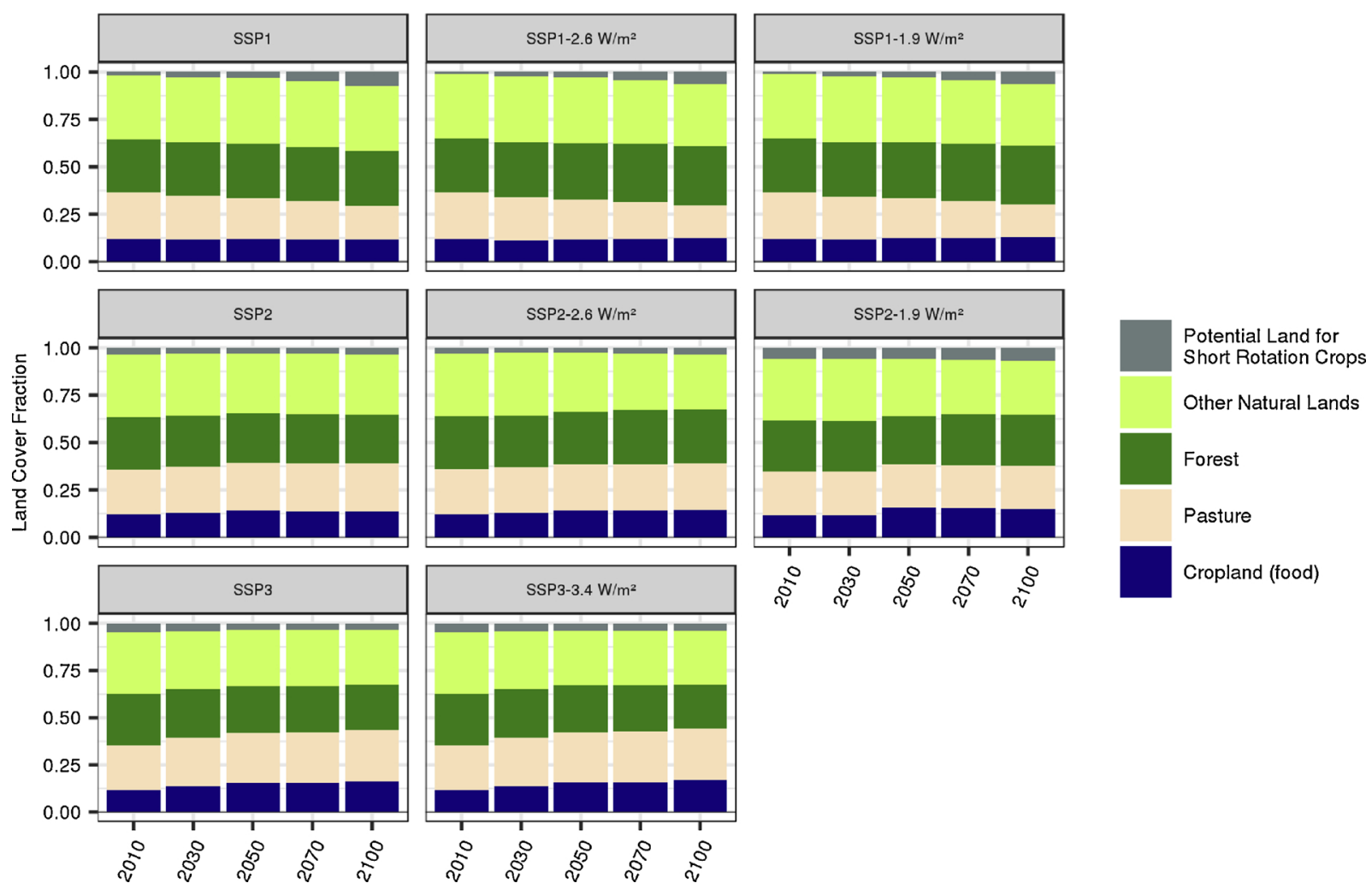

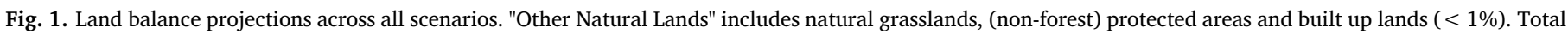
land area accounted for is $13 \mathrm{GHa}$.

\subsubsection{Energy demand and use}

The projected development of the energy system also varies across the baselines. Both primary and final energy demand are lowest in SSP1 and largest in SSP2 baselines. The lower welfare levels of the SSP3 baseline and the resultant lower per capita energy demands mean that despite its larger population, this scenario has a lower overall energy demand than SSP2. SSP1 sees a significant de-carbonization of primary energy with coal and oil largely phased out by the end of the century and with increasing importance of natural gas, modern biomass and other renewables. Note that this takes place even in the baseline, without the need for climate policy. Furthermore, high welfare levels mean that traditional biomass is completely phased out by the end of the century. The high energy demand of SSP2 and SSP3 require increased use of fossil fuels, especially coal which becomes increasingly competitive as oil and gas prices increase due to depletion (see Table A5 in the Appendix). Preferences and technological improvements also affect the supply of primary energy, especially the contribution of renewable energy.

As shown in Fig. 2, primary energy demand increases from $500 \mathrm{EJ} /$ yr in 2010 to 747, 830 and $836 \mathrm{EJ} / \mathrm{yr}$ in 2050 for the SSP1, 2 and 3 baselines respectively. In SSP1 this decreases to $700 \mathrm{EJ} / \mathrm{yr}$ by 2100 , while in SSP2 and SSP3 it continue to increase after mid-century, eventually surpassing $1000 \mathrm{EJ} / \mathrm{yr}$. The lower projection of SSP1 is a result of lower population growth as well as rapid improvements in energy intensity. Currently, fossil fuels account for $80 \%$ of primary energy use (IEA, 2017a). By 2100, these shares are projected to change to $55 \%, 79 \%$ and $84 \%$ for SSP1, 2 and 3 respectively with the latter two seeing significant increases in coal use. For all baselines, growth in electricity demand drives the changes in the final energy. This is caused by increased access to electricity and an electrification of energy functions (appliances in households, transport, etc.) as oil and gas prices increase due to depletion. However, a significant volume of liquid fuels (from fossil and biomass sources) continues to exist due to demand from the transport sector.
In order to meet the climate targets, the energy system is projected to undergo significant changes in the mitigation scenarios. For SSP12.6, SSP2-2.6 and SSP3-3.4, total primary energy demand in 2050 is projected to decrease by $25 \%, 36 \%$ and $32 \%$ compared to the respective baselines. This is due to improvements in energy efficiency and changes in behavior. By 2100 , the decrease in primary energy with respect to the baseline is $19 \%, 44 \%$ and $40 \%$, highlighting that an SSP1 world requires a lower effort than SSP2 and SSP3 to meet the climate targets. Interestingly, in SSP2 and SSP3, there is a slight resurgence in coal consumption by the end of the century. This is due to the high energy demand of these scenarios and the eventual availability of CCS technologies - prompted by high carbon taxes. For scenarios reaching a $1.5^{\circ} \mathrm{C}$ target $\left(1.9 \mathrm{~W} / \mathrm{m}^{2}\right)$, the required changes are greater with primary energy demand falling by $42 \%$ and $40 \%$ in 2050 with respect to the SSP1 and SSP2 baselines respectively. In all mitigation scenarios the use of fossil fuels decreases as the carbon taxes lead to an increased share of biomass and other renewable energy sources (see Table 2).

\subsubsection{Greenhouse gas emissions and climate change mitigation efforts}

The GHG emissions of the baselines lead to an increase in the radiative forcing (including contributions from all greenhouse gasses and forcing agents, albedo, nitrate and mineral dust) from approximately $2 \mathrm{~W} / \mathrm{m}^{2}$ currently to $3.8-4.3 \mathrm{~W} / \mathrm{m}^{2}$ in 2050 and $5-6.7 \mathrm{~W} / \mathrm{m}^{2}$ in 2100 . This leads to an increase of global mean temperatures of approximately $3-4{ }^{\circ} \mathrm{C}$ by the end of the century compared to pre-industrial levels. The upper limit refers to the SSP2 and SSP3 scenarios where GHG emissions from energy use, agriculture and LUC continue to increase. In the mitigation scenarios a carbon tax is introduced (applied to energy sources and non $-\mathrm{CO}_{2}$ gases) in order to meet the radiative forcing targets consistent with $1.5^{\circ} \mathrm{C}$ and $2{ }^{\circ} \mathrm{C}$ targets. See Figure A2 in the Appendix for projections of radiative forcing, global mean temperature change, and carbon taxes for each scenario.

The projections of baseline and mitigation emissions and their sources are shown in Fig. 3 (numerical results are presented in Table A6 

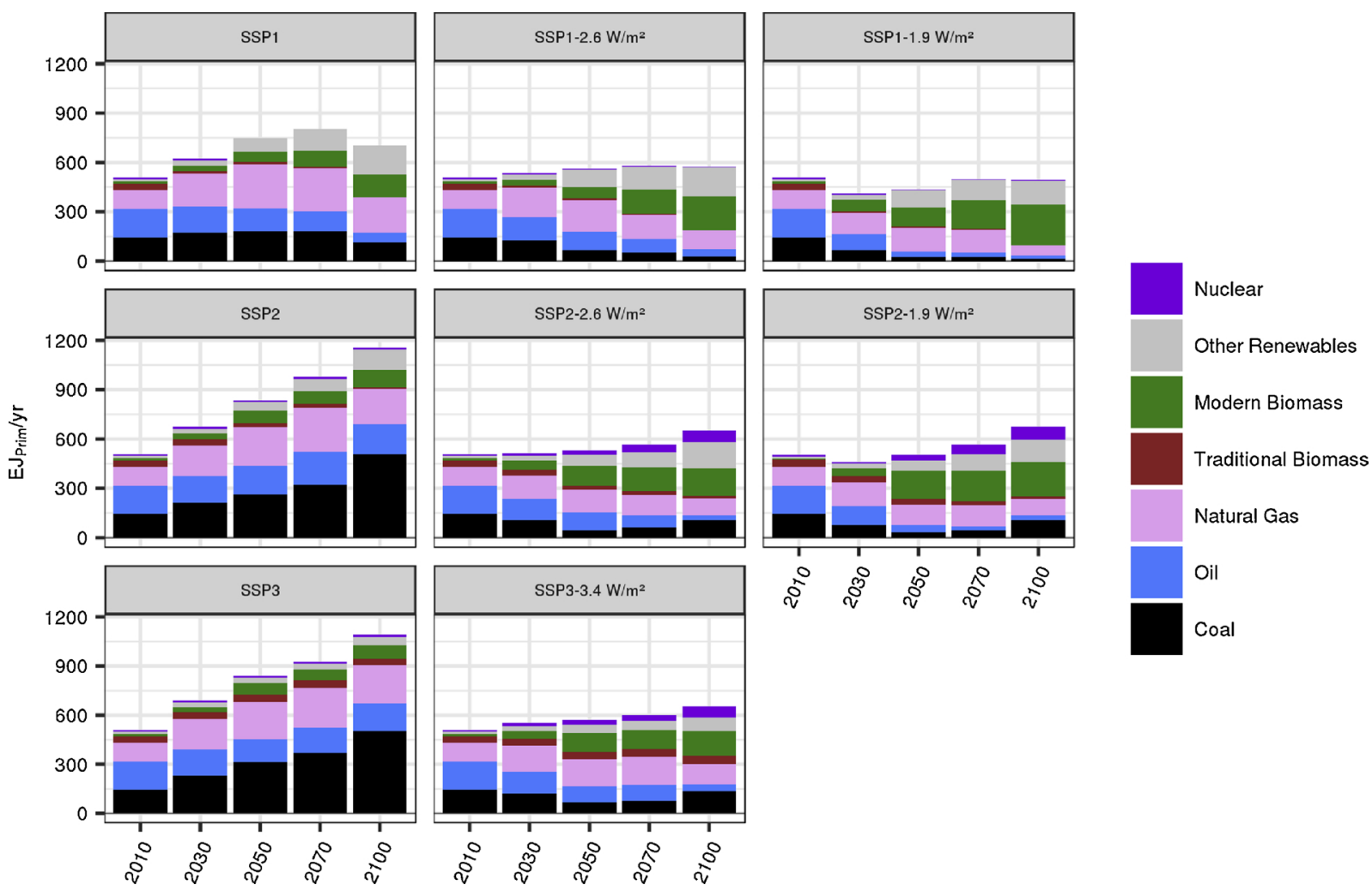

Fig. 2. Projections of primary energy in the baseline and mitigation scenarios. Disaggregated per energy source. Note SSP3 has a more lenient forcing target as the $2.6 \mathrm{~W} / \mathrm{m}^{2}$ target is infeasible (as described in Section 2.3).
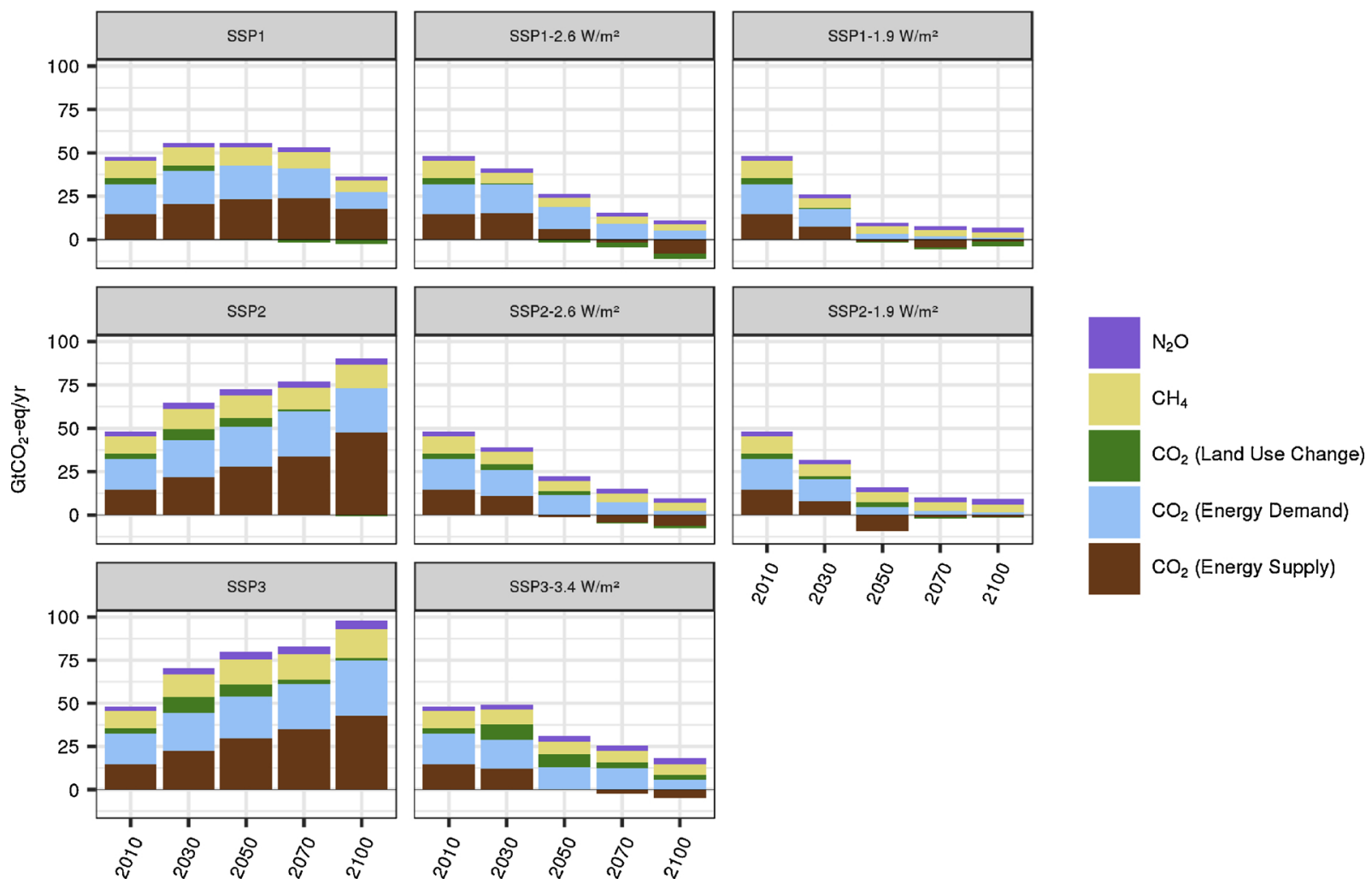

Fig. 3. Projections of greenhouse gas emissions in the baseline and mitigation scenarios. Disaggregated per emission source. Note SSP3 has a more lenient forcing target as the $2.6 \mathrm{~W} / \mathrm{m}^{2}$ target is infeasible (as described in Section 2.3 ). 
in the Appendix). Due to its lower overall population and energy intensity, the baseline emissions of SSP1 are projected to decline after 2050. In all mitigation scenarios, energy-related greenhouse gas emissions are reduced significantly compared to baseline. These arise from reduced demand due to efficiency increases, fuel switching towards cleaner sources and an increased use of CCS and bioenergy combined with CCS (BECCS), the latter of which may lead to net-negative emissions.

Concerning the land-system, as explained in Section 2.3, the mitigation scenarios have additional measures (with respect to the baseline) which constrain the loss of natural lands based on protecting carbon stocks and reforestation of degraded forest lands. This leads to a slight increase in forest land in the SSP1 and SSP2 mitigation scenarios. Consequently, although LUC $\mathrm{CO}_{2}$ emissions are projected to decrease from today's level in all the baselines, this decrease is more pronounced in the mitigation scenarios of SSP1 and SSP2. In the SSP1 and SSP2 mitigation scenarios, anthropogenic LUC emissions become negative towards the end of the century. For the SSP3 mitigation scenario, the lenient carbon stock constraints and limited reforestation combined with biomass demand lead to continued $\mathrm{CO}_{2}$ emissions throughout the projection period. These dynamics and their relationship with biomass production are discussed further in Section 3.2.4.

\subsection{Biomass supply and demand}

The land use and energy system projections outlined above lead to vastly different contexts for biomass supply and demand. These affect the availability and quality of land to grow biomass, and the competitiveness of different bioenergy options in the energy system. Consequently, the GHG emissions from biomass production and the avoided emissions from bioenergy use vary across these scenarios. In the following sections we present the different biomass supply and demand pathways according to the different baseline and mitigation scenarios, and highlight how the effectiveness of biomass as a climate mitigation measure depends on the scenario storylines.

\subsubsection{Demand of bioenergy and biochemicals}

Fig. 4 shows the projections of bioenergy and biochemical use for all the scenarios, indicating an increase in their demand throughout the projection period. The favourable technological assumptions and biomass supply curves of SSP1 (see Section 3.2.2) give this storyline the highest biomass final energy penetration, despite the fact that SSP1 has the overall lowest demand for primary and final energy (see Section $3.1 .2)$. By 2050, bio-based energy and chemicals account for over $8 \%$ of the total primary energy supply (TPES) for all the baselines, with SSP1 increasing further to $19 \%$ by 2100 . In the mitigation scenarios, the carbon tax increases the competitiveness of biomass (and other renewables) and thus drives up their demand as shown in Fig. 2 and Table 2. For the $1.9 \mathrm{~W} / \mathrm{m}^{2}$ scenarios the share of bioenergy in TPES reaches $50 \%$ for SSP1-1.9 and 32\% for SSP2-1.9 by 2100, highlighting the increased importance of biomass for strict mitigation targets. Note that when comparing SSP2-1.9 and SSP2-2.6, while the use of primary biomass increases, this is not the case for final energy based on biomass (Fig. 4). This is because in the SSP2-1.9 case the primary biomass is mostly used for the production of electricity (with CCS), which has a lower conversion efficiency than liquid fuels and hydrogen produced in the SSP2-2.6 case.

The preferred use of biomass in the baseline scenarios is in the form of liquid and solid fuels. This is due to the transport sector demanding liquid fuels amid increasing oil prices, as well as heat in the residential and industry sectors. Another important use is the production of chemicals. The relative importance of solid fuels increases in SSP2 and SSP3 baselines due to the pessimistic assumptions on the improvement of $2^{\text {nd }}$ generation biofuel technologies (details on biofuel conversion technologies across baselines can be found in Table A2 in the Appendix). In SSP1, the higher technological improvements also allow for small amounts of hydrogen to be produced ( $3 \mathrm{EJ} / \mathrm{yr}$ ) by the end of the century.
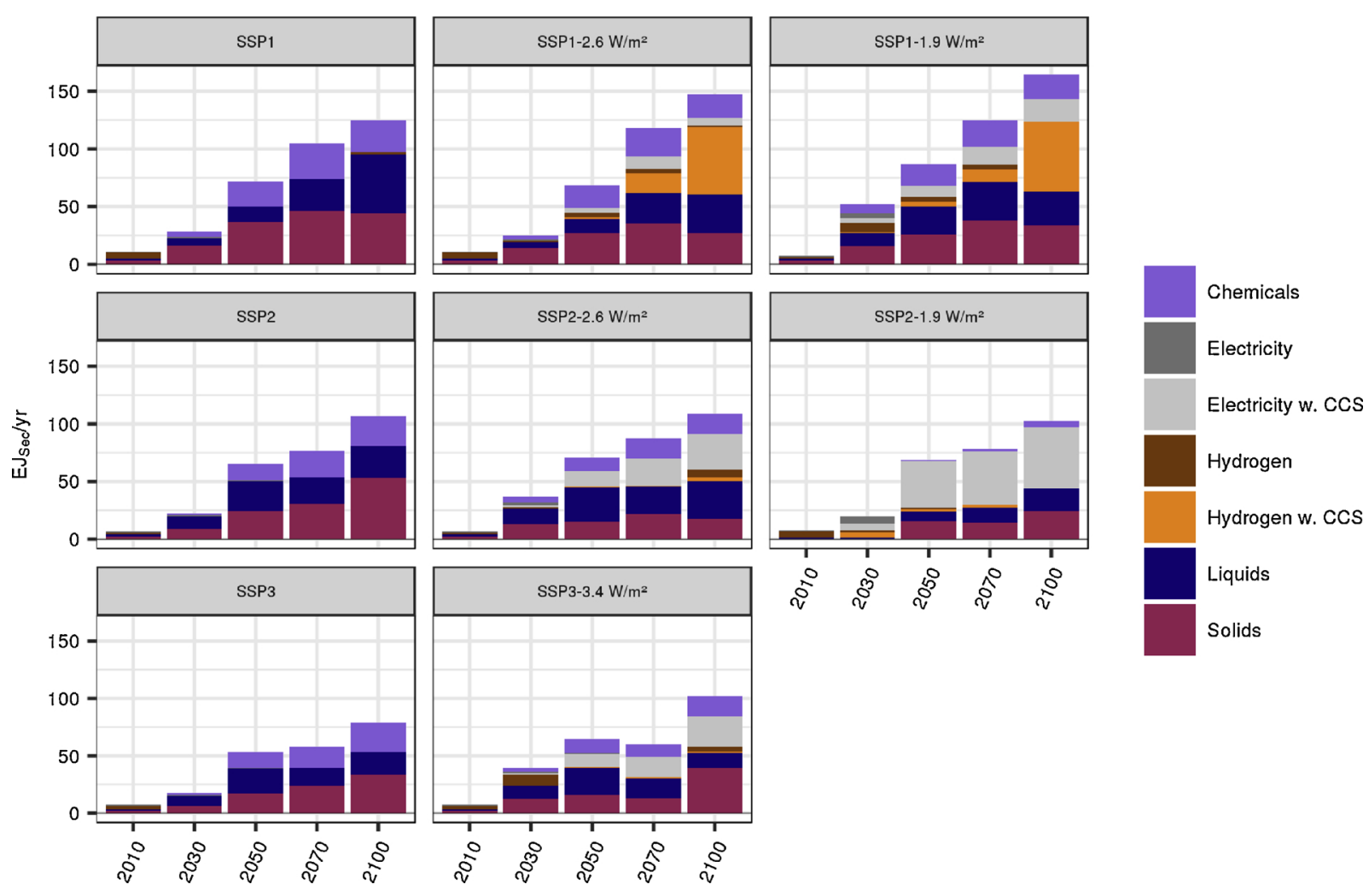

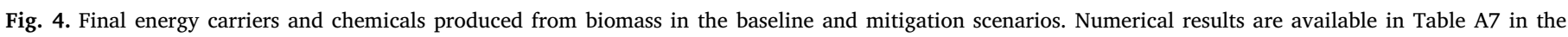
Appendix. Note SSP3 has a more lenient forcing target as the $2.6 \mathrm{~W} / \mathrm{m}^{2}$ target is infeasible (as described in Section 2.3 ). 


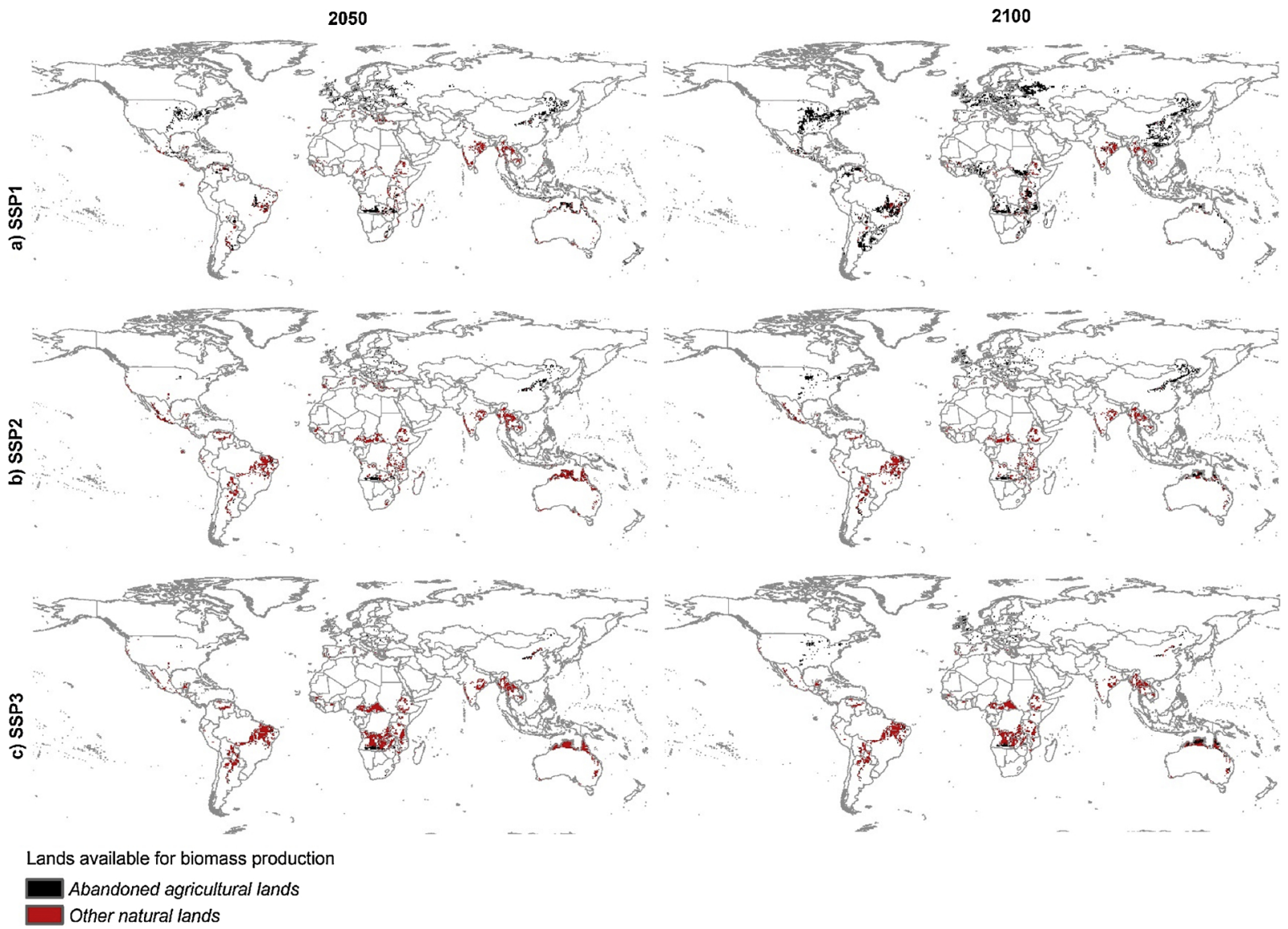

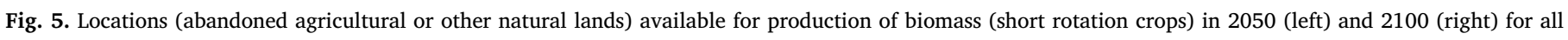
baselines. Note: Locations vary slightly in mitigation scenarios.

The increased use of bioenergy in mitigation scenarios is largely driven by the adoption of advanced bioenergy technologies (i.e. advanced biofuels, hydrogen production, and its combination with CCS in order to achieve so-called negative emissions). These advanced technologies are used primarily in the transport sector. By the end of the century, it is projected that these technologies account for $67 \%, 61 \%$ and $40 \%$ of bioenergy use in SSP1-2.6, SSP2-2.6 and SSP3-3.4 respectively. For SSP1-1.9 and SSP2-1.9 advanced technologies make up 67\% and $76 \%$ of bioenergy use. In the projections, passenger transport is decarbonized through electrification, or (bio-)hydrogen. However, the production of liquid fuels persists for aviation and freight where biofuels are the only cost-effective substitute for oil. Biomass used with BECCS technologies is crucial in IMAGE 3.0 for meeting strict climate targets, something reflected across a number of IAMs (Kriegler et al., 2014; Luderer et al., 2014). This technology is projected to become competitive in the latter half of the century, promoted by technological improvements and carbon taxes exceeding $100 \$ / \mathrm{tCO}_{2}$. It is important to note that in IMAGE 3.0 there is no representation of liquid biofuels in combination with CCS. Other IAM projections have shown that when available, this technology plays a very important role at decarbonizing the energy system and contributing to negative emissions (Bauer et al., 2018).

\subsubsection{Drivers and constraints of biomass supply}

3.2.2.1. Residues. The availability of residues depends on the production and intensity of agricultural and forestry operations, ecological constraints, and competing uses such as feed for livestock or traditional fuel use in poor households (for details see the Appendix and Daioglou et al. (2016). In the SSP1 baseline, overall agricultural and forestry production is relatively low, but the intensive nature of agriculture and the limited demand of residues for competing uses implies that a large portion of the potential residues are available. In contrast, in the SSP3 baseline high population growth (and consequent agricultural production) drives up the potential for residues. However extensive land use for agricultural production (and thus the need for a large volume of residues to maintain ecological services), and increased dependence of livestock feed and traditional fuel use on residues limits the final availability. These counteracting effects lead to similar residue potential across the three baselines (66-74 EJ/yr in 2050 and 83-84 EJ/ yr in 2100, see Table 2), with SSP1 having slightly lower costs due to geographical concentration of the supply (Fig. 6).

3.2.2.2. Energy crops. Fig. 5 shows IMAGE 3.0 maps of land availability for future energy crop production, highlighting lands classified as abandoned agricultural or other natural lands (see Section 2.2 and the Appendix for an overview of the method). As explained in Section 3.1.1, in SSP1 the eventual (post 2050) stabilization of agricultural production, together with further increases in agricultural efficiency, allows for significant volumes of abandoned agricultural lands, while the stricter environmental constraints limit the volume of other natural lands. The SSP3 baseline shows the exact opposite behavior, with SSP2 occupying a middle ground.

The type of land available is very important for the overall biomass potential, and the land-use change emissions. Abandoned agricultural lands tend to have the highest yields since these are the most attractive locations, while moving into unused lands (which tend to be of lower quality according to the allocation rules of IMAGE 3.0) results in reduced marginal yields. In IMAGE 3.0, primary biomass can be supplied by maize, sugarcane or lignocellulosic crops (including miscanthus, willow, and eucalyptus). As lignocellulosic crops have higher yields, 


\section{A: Primary Biomass Supply Curves for Different Biomass Resources and Baselines}
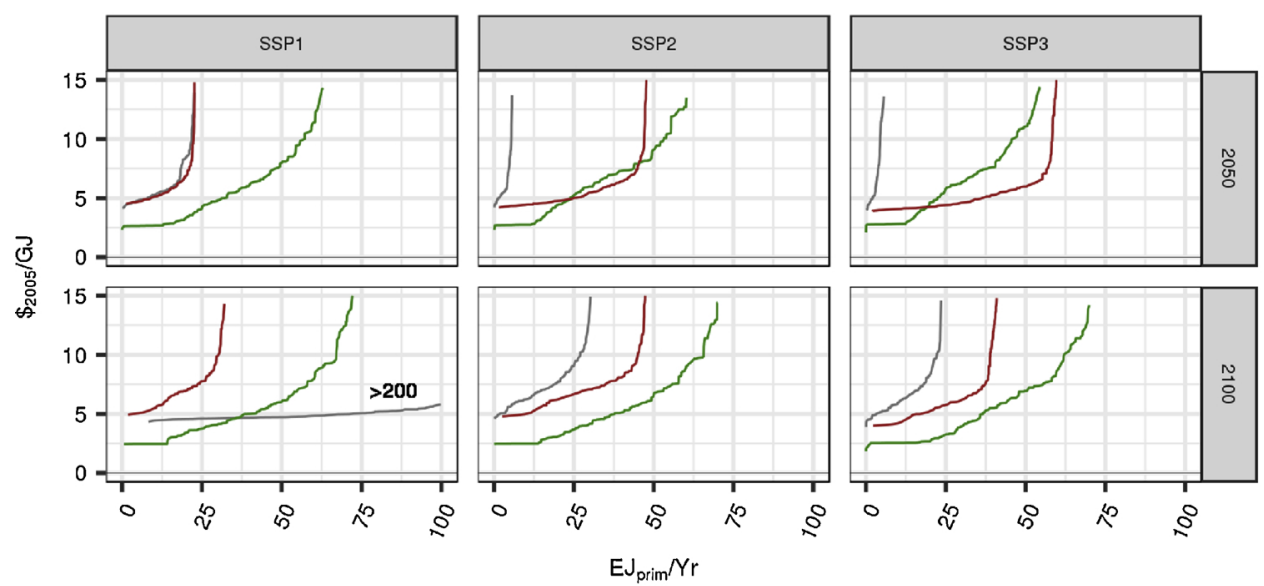

- Abandoned Lands

B. Total Primary Biomass Supply Curves Across Baselines

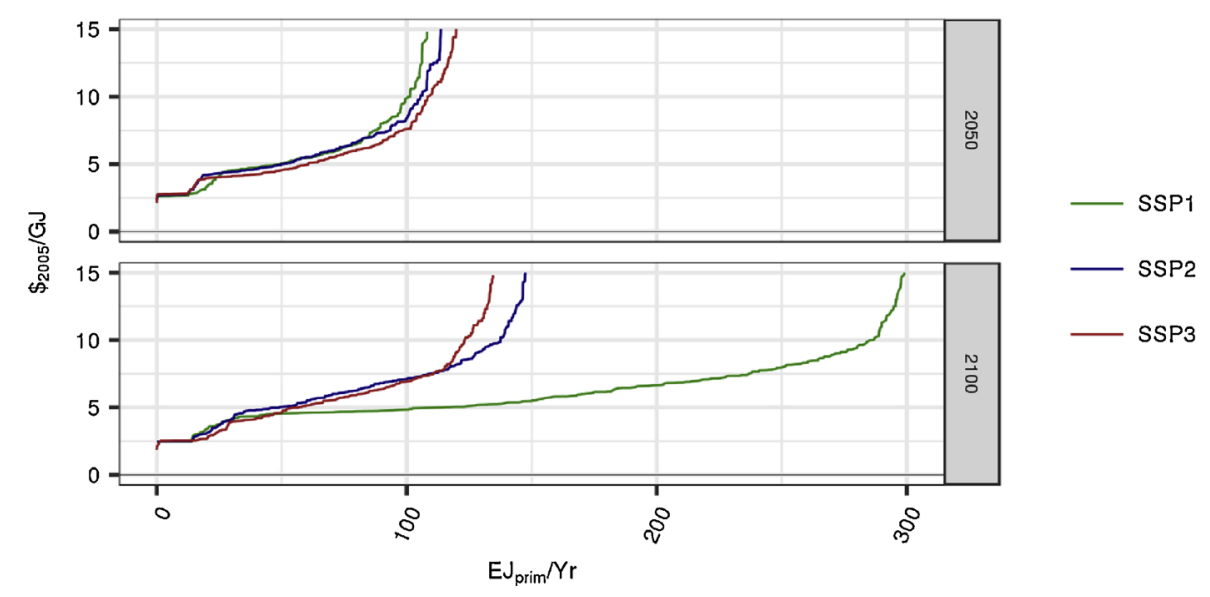

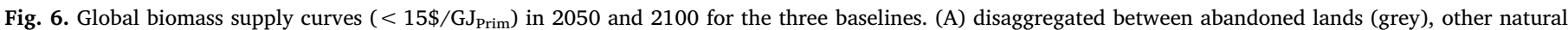

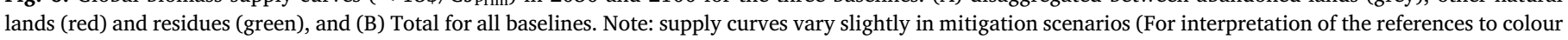
in this figure legend, the reader is referred to the web version of this article).

they have a lower land demand and thus benefit from lower costs. This makes them the preferred biomass feedstock in all projections.

Globally, aggregate yields of lignocellulosic crops are projected to increase from approximately $220 \mathrm{GJ} / \mathrm{Ha}$ today to $272 \mathrm{GJ} / \mathrm{Ha}$, for SSP1, $240 \mathrm{GJ} / \mathrm{Ha}$ for SSP2 and $247 \mathrm{GJ} / \mathrm{Ha}$ SSP3 by 2050. By 2100, yields further increase of $498 \mathrm{GJ} / \mathrm{Ha}, 330 \mathrm{GJ} / \mathrm{Ha}$ and $290 \mathrm{GJ} / \mathrm{Ha}$ for the three baselines, respectively. Potential yields across different regions and scenarios are shown in Figure A3 in the Appendix. The differences across the scenarios arise due to the varying land quality available in each case as well as improvements in management consistent with the scenario storyline. Specifically, for abandoned agricultural lands in SSP1 yields approach $300 \mathrm{GJ} / \mathrm{Ha}$ by 2050 and $500 \mathrm{GJ} / \mathrm{yr}$ by 2100 . For other natural lands, aggregate yields are $280 \mathrm{GJ} / \mathrm{yr}$ and $400 \mathrm{GJ} / \mathrm{yr}$ in 2050 and 2100, respectively. These yield improvements indicate increased efforts towards closing the yield gap globally, especially in SSP1 where global aggregate yields reflect current best practices.

Fig. 6 shows global cost-supply curves in 2050 and 2100 for primary biomass from each of the considered sources and the total across all baselines as projected by IMAGE 3.0. Overall, SSP1 has the highest long-term biomass potential despite the stricter constraints on land use. This high potential is driven by the availability of abandoned agricultural lands with high yields, as explained above. While the SSP3 baseline has more lenient constraints on land use, increases in agricultural land for food production limits biomass production to lower quality lands reducing the overall potential. Primary biomass potential is projected to be $130-140 \mathrm{EJ}_{\text {Prim }} / \mathrm{yr}$ in 2050 and $150-400 \mathrm{EJ}_{\text {Prim }} / \mathrm{yr}$ in 2100 for the baselines. As stated above, the supply from residues is relatively constant across the scenarios with availability and quality of land for energy crops forming the major uncertainty. The supply curves shown in Fig. 6 are based on the baseline projections. Due to the carbon-stock constraints and changes in agricultural production in the mitigation scenarios, the supply curves for those scenarios have minor changes but similar overall patterns.

\subsubsection{Projections of biomass production}

According to IMAGE 3.0, lignocellulosic crops (such as miscanthus, and to a lesser extent woody biomass such as willow and eucalyptus) are the dominant energy crops. These are preferred over $1^{\text {st }}$ generation sources due to their higher yields and ability to be grown in many diverse locations, which lower their supply costs.

Table 2 summarizes key indicators for biomass supply and demand across all scenarios. As shown, primary biomass production is projected to increase to $64-74 \mathrm{EJ}_{\text {Prim }} / \mathrm{yr}$ in 2050 and 78-134 $\mathrm{EJ}_{\text {Prim }} / \mathrm{yr}$ in 2100 for the baselines. In the mitigation scenarios, these numbers increase to 71 $174 \mathrm{EJ}_{\text {Prim }} / \mathrm{yr}$ in 2050 and 151-246 $\mathrm{EJ}_{\text {Prim }} / \mathrm{yr}$ in 2100. The supply from residues is relatively constant across the scenarios with energy crop production being the major uncertainty, due to differences in the availability and quality of land. As shown in Fig. 7, for all cases, residues make up most of the short term supply of primary biomass in the IMAGE 3.0 projections as they are the cheapest resource at volumes less 
Table 2

Projections of key indicators for biomass, bioenergy and biochemicals across all scenarios. "Potential" denotes volumes which are in principle available, while "Production" concerns the actual supply and demand. Note that the primary energy production of SSP2-1.9 is greater than that suggested by the supply curves presented in Fig. 6. As the SSP2 world requires very large scale bioenergy deployment in order to meet this climate target, this scenario allows biomass to be produced on lands otherwise deemed unavailable. For details see Table 1 and Doelman et al. (2018).

\begin{tabular}{|c|c|c|c|c|c|c|c|c|c|}
\hline & & \multicolumn{3}{|c|}{ Baseline } & \multicolumn{2}{|c|}{ Mitigation $\left(1.5^{\circ} \mathrm{C}\right)$} & \multicolumn{3}{|c|}{ Mitigation $\left(2-3^{\circ} \mathrm{C}\right)$} \\
\hline & & SSP1 & SSP2 & SSP3 & SSP1-1.9 & SSP2-1.9 & SSP1-2.6 & SSP2-2.6 & SSP3-3.4 \\
\hline & & & \multicolumn{7}{|c|}{ Primary Potential $\left(E J_{\text {Prim }} / y r\right)$} \\
\hline \multirow[t]{21}{*}{2050} & Residues & 74 & 74 & 66 & 72 & 71 & 72 & 71 & 66 \\
\hline & Energy Crops & 66 & 59 & 66 & 56 & 122 & 58 & 46 & 66 \\
\hline & Total & 140 & 132 & 132 & 128 & 193 & 130 & 117 & 132 \\
\hline & & & \multicolumn{7}{|c|}{ Primary Production (EJ Prim $/ y r)$} \\
\hline & Residues & 41 & 30 & 22 & 68 & 69 & 50 & 67 & 60 \\
\hline & Energy Crops & 23 & 43 & 45 & 47 & 105 & 21 & 54 & 56 \\
\hline & Total & 64 & 74 & 68 & 114 & 174 & 71 & 120 & 116 \\
\hline & & & \multicolumn{7}{|c|}{ \% of Total Primary Energy Supply } \\
\hline & Biomass & $9 \%$ & $9 \%$ & $8 \%$ & $26 \%$ & $35 \%$ & $13 \%$ & $23 \%$ & $20 \%$ \\
\hline & Fossil & $79 \%$ & $81 \%$ & $82 \%$ & $47 \%$ & $41 \%$ & $67 \%$ & $55 \%$ & $59 \%$ \\
\hline & Other Ren. & $12 \%$ & $10 \%$ & $10 \%$ & $27 \%$ & $25 \%$ & $21 \%$ & $22 \%$ & $21 \%$ \\
\hline & & & \multicolumn{7}{|c|}{ Potential Land for Biomass (MHa) } \\
\hline & & 424 & 412 & 472 & \multicolumn{2}{|c|}{ Similar to baseline } & \multicolumn{3}{|c|}{ Similar to baseline } \\
\hline & & & \multicolumn{7}{|c|}{ Land Use for Biomass Production (MHa) } \\
\hline & & 84 & 181 & 184 & 172 & 438 & 78 & 223 & 226 \\
\hline & & & \multicolumn{7}{|c|}{ Secondary Bioenergy, incl. feedstocks $\left(E J_{S e c} / y r\right)$} \\
\hline & w CCS & 0 & 0 & 0 & 13 & 43 & 5 & 15 & 12 \\
\hline & w/o CCS & 72 & & & 74 & 26 & 64 & 49 & 42 \\
\hline & & & \multicolumn{7}{|c|}{ \% Total Final Consumption } \\
\hline & & $13 \%$ & $11 \%$ & $9 \%$ & $27 \%$ & $20 \%$ & $16 \%$ & $15 \%$ & $13 \%$ \\
\hline & & & \multicolumn{7}{|c|}{ Primary Potential $\left(E J_{\text {Prim }} / y r\right)$} \\
\hline \multirow[t]{20}{*}{2100} & Residues & 83 & 84 & 83 & 81 & 82 & 81 & 82 & 83 \\
\hline & Energy Crops & 314 & 90 & 66 & 276 & 223 & 276 & 91 & 68 \\
\hline & Total & 397 & 174 & 149 & 357 & 305 & 357 & 173 & 151 \\
\hline & & & \multicolumn{7}{|c|}{ Primary Production (EJ Prim $/ y r)$} \\
\hline & Residues & 52 & 59 & 38 & 80 & 77 & 69 & 81 & 83 \\
\hline & Energy Crops & 82 & 46 & 41 & 166 & 136 & 135 & 88 & 68 \\
\hline & Total & 134 & 105 & 78 & 246 & 213 & 203 & 169 & 151 \\
\hline & & & \multicolumn{7}{|c|}{$\%$ of Total Primary Energy Supply } \\
\hline & Biomass & $19 \%$ & $9 \%$ & $7 \%$ & $50 \%$ & $32 \%$ & $36 \%$ & $26 \%$ & $23 \%$ \\
\hline & Fossil & $55 \%$ & $79 \%$ & $84 \%$ & $19 \%$ & $35 \%$ & $33 \%$ & $37 \%$ & $47 \%$ \\
\hline & Other Ren. & $25 \%$ & $12 \%$ & $9 \%$ & $30 \%$ & $33 \%$ & $32 \%$ & $36 \%$ & $30 \%$ \\
\hline & & & \multicolumn{7}{|c|}{ Potential Land for Biomass (MHa) } \\
\hline & & 987 & 480 & & Similar to & & Similar to & & \\
\hline & & & \multicolumn{7}{|c|}{ Land Use for Biomass Production (MHa) } \\
\hline & & 165 & 139 & 141 & 334 & 414 & 270 & 268 & 234 \\
\hline & & & \multicolumn{7}{|c|}{ Secondary Bioenergy, incl. feedstocks $\left(E J_{S e c} / y r\right)$} \\
\hline & w CCS & 0 & 0 & 0 & 80 & 43 & 65 & 34 & 28 \\
\hline & w/o CCS & 125 & & & 84 & 40 & 82 & 74 & 74 \\
\hline & & & \multicolumn{7}{|c|}{ \% Total Final Consumption } \\
\hline & & $20 \%$ & $13 \%$ & $10 \%$ & $46 \%$ & $18 \%$ & $34 \%$ & $23 \%$ & $20 \%$ \\
\hline
\end{tabular}

than 25-30 EJ/yr (see supply curves in Fig. 6). This finding is consistent with several other IAM models (Popp et al., 2014; Rose et al., 2014). While residues dominate biomass supply in the short term, the annual potential of this low-cost resource is limited to less than $80 \mathrm{EJ} / \mathrm{yr}$. Improvements in yields of energy crops (and thus lower costs) as well as increased demand means that after mid-century energy crops become the dominant primary source of biomass. This is especially the case for SSP1 and SSP2, which have higher biomass demands.

Fig. 8 shows the projected production of residues and energy crops across all scenarios for five different world regions. Asia and OECD are the most important supply regions for residues since they produce crops with high residue potential (maize, rice and oil crops) and lower volumes of residues are diverted for ancillary uses such as livestock feed or cooking/heating fuel in poor households (Daioglou et al., 2016). For energy crops, in the SSP1 baseline, Latin America and Reforming Economies (consisting of countries of the Former Soviet Union) are projected to become increasingly important, while in the SSP3 baseline Asia and OECD regions (which are the main consumers) increase their relative production due to trade barriers in this baseline. For details on the how international trade of biomass is modelled see the Appendix.
In the mitigation scenarios, the relative importance of the Asia and OECD regions increases, accounting for approximately $30 \%$ each of the total supply. This is because in the mitigation scenarios land with high carbon stocks are protected, thus limiting further expansion in Latin America and Africa. Furthermore, as mentioned above, Asia and the OECD continue being important as supply regions of residues in the mitigation scenarios. For all scenarios, Latin America and the former Soviet Union each provide about $5-15 \%$ of the global demand, while the Middle East and Africa provide 10-30\%.

\subsubsection{Land use change emissions due to biomass production}

The effect of biomass production on LUC emissions depends on the quality of available land for biomass (Section 3.2.2) and the production of biomass from energy crops (Section 3.2.3). In the above scenarios, the carbon stock constraints applied in the mitigation scenarios affect the allocation of biomass production and thus the associated LUC emissions. This can be seen in Fig. 9 which displays the projections of energy crop production and overall LUC emissions for all scenarios. Although the SSP1 scenarios have the highest biomass demand, they also have the lowest LUC emissions due to the availability of high 

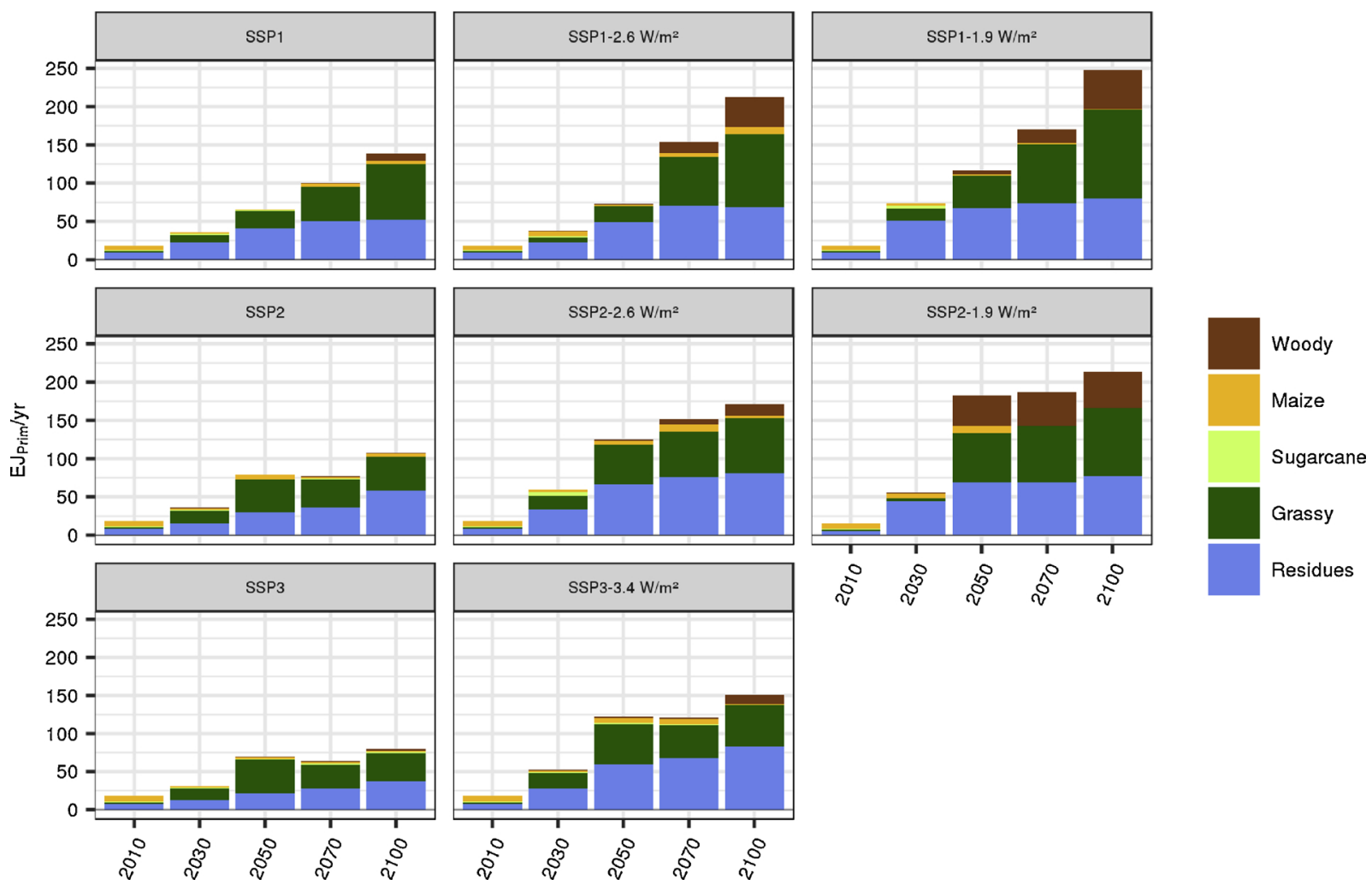

Fig. 7. Primary biomass production for different feedstocks for all scenarios. Note SSP 3 has a more lenient forcing target as the $2.6 \mathrm{~W} / \mathrm{m}^{2}$ target is infeasible (as described in Section 2.3).
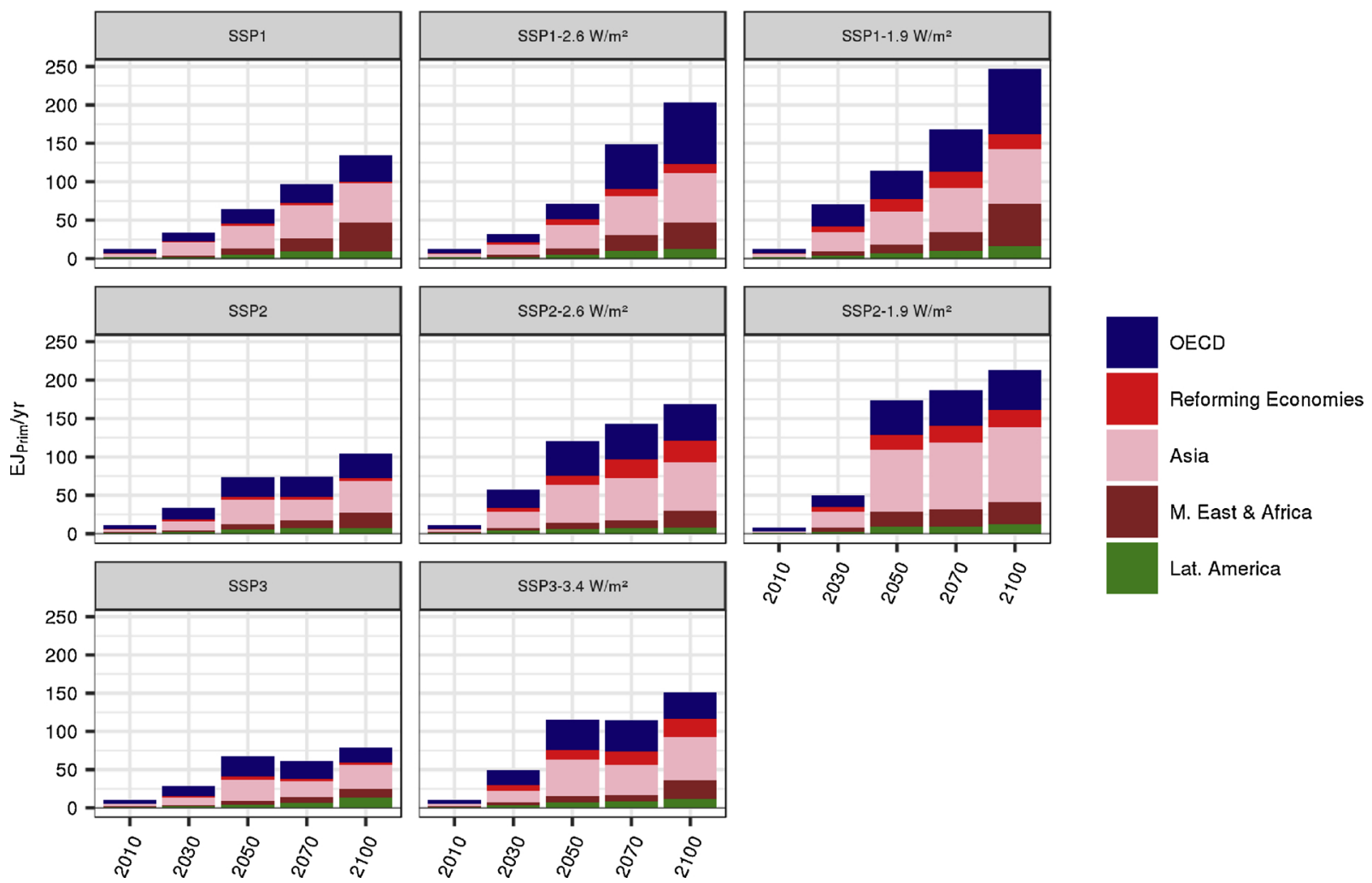

Fig. 8. Primary biomass production disaggregated across production regions for all scenarios. Note SSP 3 has a more lenient forcing target as the $2.6 \mathrm{~W} / \mathrm{m}^{2}$ target is infeasible (as described in Section 2.3). 

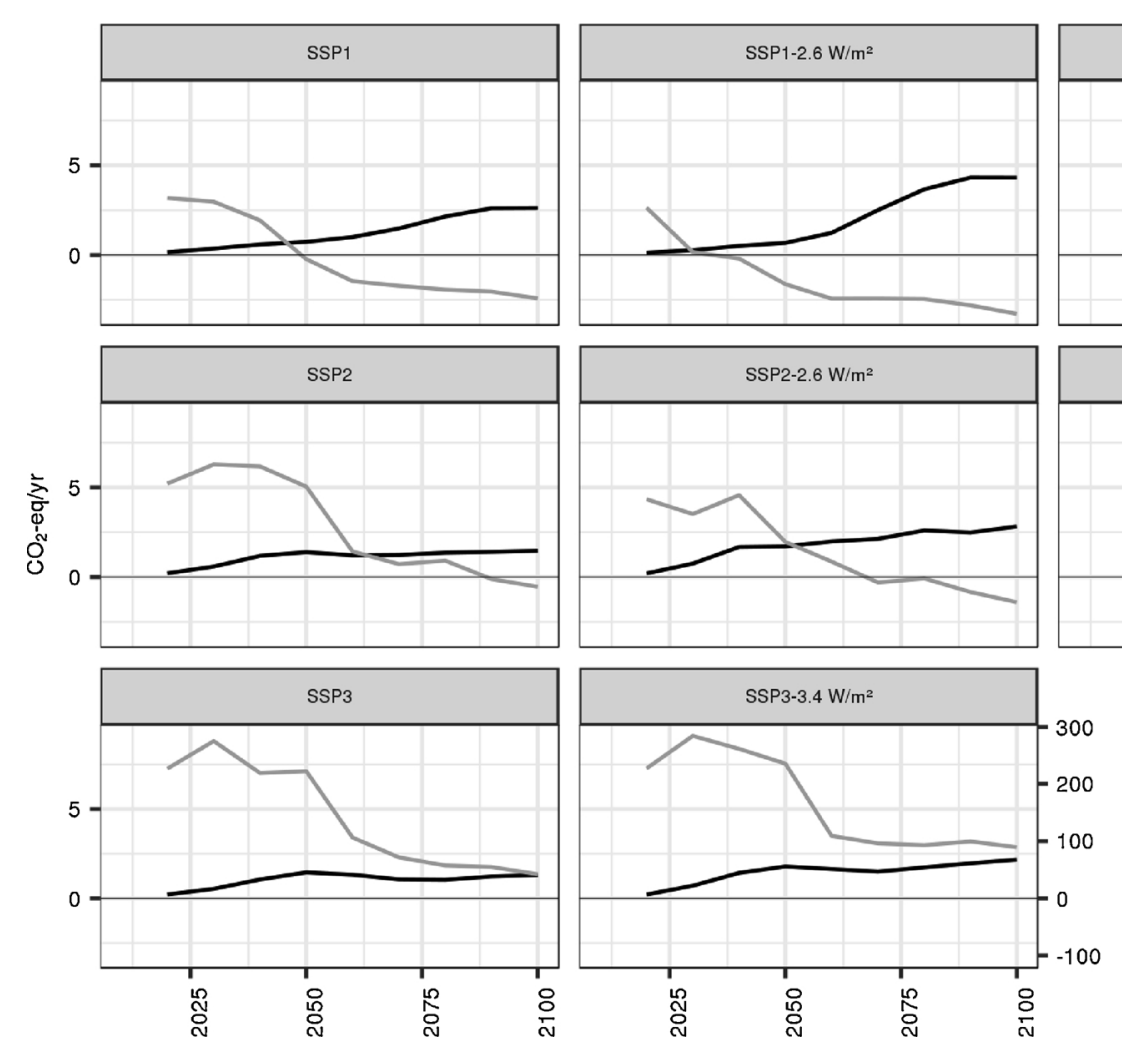
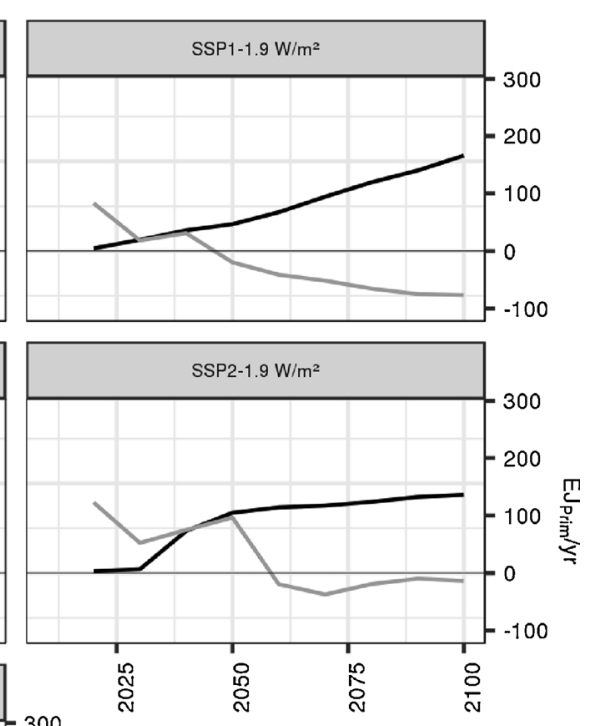

- Land Use Change Emissions

- Biomass (Energy Crops)

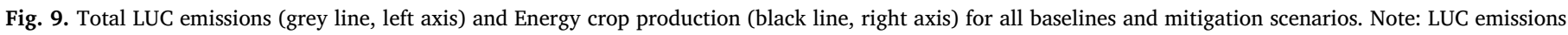

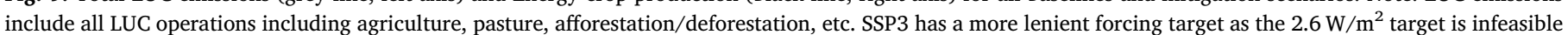
(as described in Section 2.3).

quality abandoned agricultural lands. This is opposed to the other baselines where biomass production largely depends on natural lands due to the lack of availability of abandoned agricultural lands (there is overall agricultural expansion) and more lenient constraints on natural lands compared to SSP1. Furthermore, despite the fact that the demand for energy crops in SSP1-2.6 increases by $64 \%$ with respect to its baseline, the land sector acts as a carbon sink from an earlier moment in time than in the respective baseline and achieves deeper negative emissions. This is due to the additional carbon stock constraints applied in the mitigation scenario. Thus, the overall disturbance of carbonstocks is very low.

In SSP3-3.4, a smaller increase in energy crop demand with respect to its baseline (and overall lower volumes than SSP1-2.6) leads to a doubling of LUC emissions (compared to its baseline) in 2100 as the carbon stocks of unprotected natural lands are affected. The carbon stock constraints are most effective when comparing the SSP2 baseline with its mitigation scenarios. This baseline sees increasing demand of agriculture throughout the projection period, and although LUC emissions decrease, they only become negative towards the end of the century. In this case the application of the carbon stock constraint in the mitigation scenarios leads to negative LUC emissions after 2050, despite maintaining agricultural production and more than doubling the demand of energy crops. It is worth noting that the when comparing the 1.9 and $2.6 \mathrm{~W} / \mathrm{m}^{2}$ scenarios, the former scenarios show higher LUC emissions for both the SSP1 and SSP2 cases. This is due to the increased demand for biomass. This is compensated through increased use of BECCS, as shown in Fig. 4 and Table 2.

\section{Discussion}

Biomass production, unless from residues, requires land which raises concerns related to land-use change emissions. LUC emissions vary significantly across different landscapes, and a limited volume of biomass can be produced at LUC emission levels deemed acceptable for climate mitigation efforts (Daioglou et al., 2017; Fargione et al., 2008). In the above analysis, the relationship between biomass production and LUC emissions, and how this varies across scenarios, has been highlighted in Section 3.2.4. As the model set-up assumes an idealised "food-first" principle, we do not explicitly deal with land competition between food and fuel production, and consequently we also do not deal with the so-called indirect LUC (ILUC) (Searchinger et al., 2008). Instead, our purpose is to explore the potential of biomass to contribute to climate change mitigation which would be consistent with avoiding deforestation and competition with food production, and how its contribution is sensitive to different socio-economic scenarios. Moreover, ILUC emissions have been shown to be exacerbated by, among others, the production of oil-crop based biofuels, low food and fuel crop yields, and the lack of land protection measures (Wicke et al., 2012; Plevin et al., 2015). This highlights the favourable nature of the SSP1 implementation where strict land utilization constraints, improved crop yields and the reduction of extensive pastures would allow for low LUC/ ILUC emissions of biomass production, as well as land-based mitigation.

Due to up-front emissions from LUC and ILUC, biomass produced from energy crops may only offer serious mitigation benefits when used in long term contexts, as in these projections. This is often framed as the "carbon-debt" of biomass. However, policy and investment time horizons may be limited to 30 years or less (EU, 2009; EPA, 2010). Research conducted with the IMAGE model recently highlighted that the volume of biomass which can contribute to climate mitigation with such short accounting periods is very limited, implying that the effective use of biomass as a climate mitigation measure would require production in a given location over a longer time period (Daioglou et al., 2017). In order to avoid situations where short-termism leads to the interruption of biomass production at a given location before the carbon-debt is paid off, it is important to ensure that policies and policy continuity allow for long-term production. Improvements are also 
needed in the underlying carbon-stock data used in such assessments to allow for a better understanding on where biomass production should be avoided, and where it could have a positive effect (i.e. degraded areas). Additionally, as the increased use of biomass is likely be supplied through international trade (Matzenberger et al., 2015), the protection of ecosystem services would ideally be achieved through international mechanisms in order to avoid carbon leakage (Popp et al., 2014; Overmars et al., 2014).

While this paper focused on the GHG emission impacts of the land and energy systems, environmental and social issues including impacts on biodiversity, water availability and quality, food versus fuel, land tenure and security, and poverty alleviation have been highlighted as a important issues. This is particularly true for Sub-Saharan Africa which is potentially an important supply region. However, insufficient understanding of the different tradeoffs or potential synergies between bioenergy production and socio-environmental effects pose barriers to effective policy design which would allow the production of biomass without the negative side effects (Gasparatos et al., 2015; Amigun et al., 2011; Searchinger et al., 2015). The supply of biomass may lead to other environmental effects and logistical issues which are not directly assessed in the above projections. For instance, the use of residues raises a number of issues. The supply methodology assumes that a given volume has to remain in the field in order to avoid erosion and other negative environmental effects, the exact relationship between residue removal and yields, soil carbon, nutrient and hydrological cycles is still unclear and requires further research. Additionally, an improved understanding of the tradeoffs of different residue uses (bioenergy, livestock feed, left on the soil) would allow for an optimized use of residues in energy, agriculture and livestock systems. Furthermore, in our assessment we assume that biomass (residues and energy crops) provided from a number of crops and forestry operations are homogenous in quality and we only account for differences in heating values and moisture contents. This assumption allows for an explicit simplification concerning the seasonality of certain biomass resources (as we assume that the availability of different supply streams can maintain a consistent supply), international trade, and substitution between biomass feedstocks; all of which are important components of the results. Other challenges exist concerning the dispersed nature of biomass resources, and the required BECCS infrastructure implied by the projections. These issues are included in our supply curves of biomass and BECCS technologies in a stylized manner (see the Appendix for details), and our results are in line with techno-economic analyses (Moreira et al., 2016; Kemper, 2015; da Silva et al., 2018; Tagomori et al., 2018). Nonetheless, the required infrastructure to ensure the supply, trade, conversion, and transport and storage of $\mathrm{CO}_{2}$ poses significant difficulties which may affect the feasibility of our results. Future analyses should focus on the variable and heterogeneous nature of biomass feedstocks, and the feasibility of the implementation of large-scale bioenergy systems such as those projected here.

As described in Section 3.2.2, all presented scenarios assume some form of improvement in crop yields, with SSP1 having the highest and SSP3 the lowest. The resultant yields for perennial grasses and shortrotation lignocellulosic crops are within the current and projected productivity ranges (Boehmel et al., 2008; Gerssen-Gondelach et al., 2014). The figures imply aggregate energy crop yields increasing by $0.2-0.9 \%$ per year $(2010-2100)$. It is important to note that improvement rates vary depending on crop and location. These are global aggregate improvement rates for perennial grasses as projected in IMAGE 3.0 . Woody crops are slightly lower $(0.4 \%-0.5 \%)$ and sugarcane crops are higher $(0.6 \%-0.8 \%)$. These growth rates are slightly lower than those historically observed in food crops which have been shown to range between 0.7-1.6\% per year between 1961 and 2010 (GerssenGondelach et al., 2015). Yet, maintaining such yield growth rates of such a long period of time is very ambitious and requires targeted policies and investments.

Our results are sensitive to the availability of bioenergy and other low GHG emission technologies, as well as the timing of advanced technology availability (especially for advanced biofuels and BECCS). As mentioned, IMAGE 3.0 projects significant use of coal for power production in the baseline, and replacing that coal is an effective way for biomass to mitigate emissions, especially if implemented early on. However, if the electricity sector could be decarbonized early enough with other renewables, then more biomass could be directed towards transport where it is most competitive, especially if biofuels can be combined with CCS (Möllersten et al., 2003). This behavior is displayed by other IAMs, which either include liquids with CCS or have more optimistic assumptions on the availability and costs of other renewables (Muratori et al., 2017; Rose et al., 2014; Luderer et al., 2014; Klein et al., 2014; Daioglou et al., forthcoming). Similarly, the increased adoption of technologies that would reduce the demand of solid biomass as a heating fuel in the residential sector (improved insulation, heat pumps, solar collectors, etc.) would further allow for this resource to be converted to higher value and mitigation potential energy carriers.

\section{Conclusions}

This paper has presented integrated and internally consistent scenarios of biomass supply and use, and its potential contribution to climate change mitigation. The results highlight that while biomass can supply a significant portion of primary energy demand at low - or negative - LUC emissions, these parallel goals are sensitive to uncertain economic, technical and policy futures. The results can be used to identify a number of areas on which policy could focus in order to attain low GHG emission paths for biomass and bioenergy, and also highlight areas where further research is needed.

Biomass has an important role to play in future energy supply, irrespective of technological development or climate goals. Biomass forms at least $8 \%$, and up to $35 \%$ of total primary energy supply by 2050 in all the baseline and mitigation scenarios presented, with its contribution increasing in mitigation scenarios. In scenarios meeting ambitious "Paris style" climate targets, bioenergy makes up $26-35 \%$ of primary energy in 2050 and $32-50 \%$ in 2100 , primarily used in the transport and power production sectors. After 2050, in order to meet climate targets bioenergy is increasingly combined with CCS, providing so-called negative emissions which are very important when realizing the strict emission constraints of ambitious climate targets.

Mitigation scenarios depend on the availability of affordable lignocellulosic (2nd generation) biofuels and carbon capture and storage (from both fossil and biomass feedstocks). In climate mitigation scenarios, such advanced technologies account for $25-74 \%$ and $40-76 \%$ of bioenergy use in 2050 and 2100 , respectively. Additionally, there are important synergies between the development of these advanced technologies and efficiency gains in the energy system. Bioenergy can meet heat demand in buildings and industry at a low cost, however these are not the best uses for emission mitigation, as production of liquid biofuels and/or combination with CCS would help decarbonize sectors such as transport which otherwise have significant difficulty in decarbonizing. In our scenario analysis, scenarios with such technological improvements could meet very stringent climate targets with relatively low carbon taxes. Improvements in energy intensity of buildings and different transport modes can help limit the need for biomass (thus avoiding land-use change and its associate issues), and direct biomass towards uses where it can act as a more effective climate change mitigation measure. Energy and climate policies should be designed with such tandem approaches in order to optimize the use of this resource.

Residues and lignocellulosic crops provide the most attractive feedstock in terms of availability, costs and associated emissions. Residues can form a significant low cost and low emission source, even when taking into account ecological constraints and other current uses. At low demand levels, biomass is projected to be supplied almost 
entirely by residues, while with increasing demand ( $>20 \mathrm{E} J_{\text {Prim }} / \mathrm{yr}$ ) energy crops become the predominant supply source. Lignocellulosic crops, particularly perennial grasses are the preferred crop due to their comparatively high yields (and thus lower costs), their diverse range of applications for energy and chemicals, and their short growing cycles. This is in contrast with current biofuel production which predominantly depends on food crops (IEA, 2017b; WBA, 2016).

High land requirements for energy production, together with other types of land use, run the risk of causing land-use change emissions, which make biomass and bioenergy less effective at mitigating climate change. As shown in our analysis, it is possible to produce large volumes of biomass while also having net negative land use change emissions. This however requires increases in productivity of both energy and food crops as well as livestock. Minimizing land required for food production (especially pasture) would allow for the availability of large volumes of highly productive land for biomass production, at low LUC emissions. Furthermore, it is important to ensure the protection of natural lands with high carbon stocks and other ecosystem services.

\section{Acknowledgements}

This work was conducted within the research program "Knowledge Infrastructure for Sustainable Biomass" and was funded by the Dutch ministries of 'Economic Affairs, Agriculture and Innovation' and 'Infrastructure and Environment'.

\section{References}

Amigun, B., Musango, J.K., Stafford, W.J.R., Reviews, S.E., 2011. Biofuels and sustainability in Africa. Renew. Sustain. Energy Rev. 15, 1360-1372.

Bauer, N., Calvin, K., Emmerling, J., Fricko, O., Fujimori, S., Hilaire, J., Eom, J., Krey, V., Kriegler, E., Mouratiadou, I., Sytze De Boer, H., Van Den Berg, M., Carrara, S., Daioglou, V., Drouet, L., Edmonds, J.E., Gernaat, D., Havlik, P., Johnson, N., Klein, D., Kyle, P., Marangoni, G., Masui, T., Pietzcker, R.C., Strubegger, M., Wise, M., Riahi, K., Van Vuuren, D.P., 2017. Shared socio-economic pathways of the energy sector quantifying the narratives. Glob. Environ. Chang. Part A 42, 316-330.

Bauer, N., Rose, S., Fujimori, S., Van Vuuren, D., Weyant, J., Wise, M., Cui, Y., Daioglou, V., Gidden, M., Kato, E., Kitous, A., Sands, R., Sano, F., Strefler, J., Leblanc, F., Tsutsui, J., Bibas, R., Fricko, O., Hasegawa, T., Klein, D., Kurosawa, A., Mima, S., Muratori, M., 2018. Global energy sector emission reductions and bio-energy use: overview of the EMF-33 model comparison. Clim. Change 16.

Boehmel, C., Lewandowski, I., Claupein, W., 2008. Comparing annual and perennial energy cropping systems with different management intensities. Agric. Syst. 96, 224-236.

Calvin, K., Wise, M., Luckow, P., Kyle, P., Clarke, L., Edmonds, J., 2016. Implications of uncertain future fossil energy resources on bioenergy use and terrestrial carbon emissions. Clim. Change 136, 57-68.

Clarke, L., Jiang, K., Akimoto, K., Babiker, M.G.B., Fisher-Vanden, K., Hourcade, J.C., Krey, V., Kriegler, E., Löschel, A., Mccollum, D., Paltsev, S., Rose, S., Shukla, P.R., Tavoni, M., Van Der Zwaan, B., Van Vuuren, D.P., 2014. Assessing transformation pathways. In: Edenhofer, O., Pichs-Madruga, R., Sokona, Y., Farahani, E., Kadner, S., Seyboth, K., Adler, A., Baum, I., Brunner, S., Eikemeier, P., Kriemann, B., Savolainen, J., Schlömer, S., Von Stechow, C., Zwickel, T., Minx, J.C. (Eds.), Climate Change 2014: Mitigation of Climate Change. Contribution of Working Group III to the Fifth Assessment Report of the Intergovernmental Panel on Climate Change. Cambridge University Press, Cambridge, United Kingdom and New York, NY, USA.

Collins, M., Knutti, R., Arblaster, J., Dufresne, J.L., Fichefet, T., Friedlingstein, P., Gao, X., Gutowski, W.J., Johns, T., Krinner, G., Shongwe, M., Tebaldi, C., Weaver, A.J., Wehnes, M., 2013. Long-term climate change: projections, commitments and irreversibility. In: Stocker, T.F., Qin, D., Plattner, G.K., Tignor, M., Allen, S.K., Boschung, J., Nauels, A., Xia, Y., Bex, V., Midgley, P.M. (Eds.), Climate Change 2013: The Physical Science Basis. Contribution of Working Group I to the Fifth Assessment Report of the Intergovenmental Panel on Climate Change. Cabridge University Press, Cambridge, United Kingdom and New York, NY, USA.

Da Silva, F.T., Carvalho, F.M., Corrêa, J.L.G., Merschmann, P.R.D.C., Tagomori, I.S., Szklo, A., SCHAEFFER, R., 2018. CO 2 capture in ethanol distilleries in Brazil: designing the optimum carbon transportation network by integrating hubs, pipelines and trucks. Int. J. Greenh. Gas Control. 71, 168-183.

Daioglou, V., Doelman, J.C., Stehfest, E., Müller, C., Wicke, B., Faaij, A., Van Vuuren, D. 2017. Greenhouse gas emission curves for advanced biofuel supply chains. Nat. Clim. Chang. 7, 920-924.

Daioglou, V., Faaij, A.P.C., Saygin, D., Patel, M.K., Wicke, B., Van Vuuren, D.P., 2014 Energy demand and emissions of the non-energy sector. Energy Environ. Sci. 7, 482-498.

Daioglou, V., Rose, S., Bauer, N., Kitous, A., Muratori, M., Sano, F., Fujimori, S., Gidden, M., Kato, E., Keramidas, K., Klein, D., Leblanc, F., Tsutsui, J., Wise, M., Van Vuuren,
D., 2018. Bioenergy technologies and climate change mitigation pathways: results from the EMF33 study. forthcoming. Clim. Change.

Daioglou, V., Stehfest, E., Wicke, B., Faaij, A., Van Vuuren, D.P., 2016. Projections of the availability and cost of residues from agriculture and forestry. Gcb Bioenergy 8, 456-470.

Doelman, J.C., Stehfest, E., Tabeau, A., Van Meijl, H., Lassaletta, L., Gernaat, D., Hermans, K., Harmsen, M., Daioglou, V., Biemans, H., Van Der Sluis, S., Van Vuuren, D., 2018. Exploring SSP land-use dynamics using the IMAGE model: regional and gridded scenarios of land-use change and land-based climate change mitigation. Glob. Environ. Chang. Part A 48, 119-135.

Dornburg, V., Van Vuuren, D., Van De Ven, G., Langeveld, H., Meeusen, M., Banse, M., Van Oorschot, M., Ros, J., Jan Van Den Born, G., Aiking, H., Londo, M., Mozaffarian, H., Verweij, P., Lysen, E., Faaij, A., 2010. Bioenergy revisited: key factors in global potentials of bioenergy. Energy Environ. Sci. 3, 258.

EPA, 2010. Renewable Fuel Standard Program (RFS2) Regulatory Impact Analysis. United States Environmental Protection Agency.

EU, 2009. Directive 2009/28/EC of the European Parliament and of the Council of 23 April 2009. Off. J. Eur. Union L 140, 47.

FAO, 2013. FAO Statistical Yearbook 2013. Food and Agriculture Organization of the United Nations, Rome.

Fargione, J., Hill, J., Tilman, D., Polasky, S., Hawthorne, P., 2008. Land clearing and the biofuel carbon debt. Science 319, 1235-1238.

Fujimori, S., Hasegawa, T., Masui, T., Takahashi, K., Herran, D.S., Dai, H., Hijioka, Y., Kainuma, M., 2017. SSP3: AIM implementation of shared socioeconomic pathways. Glob. Environ. Chang. Part A 42, 268-283.

Gasparatos, A., Von Maltitz, G.P., Johnson, F.X., Lee, L., Mathai, M., De Oliveira, J.P., Willis, K.J.J.R., Reviews, S.E., 2015. Biofuels in sub-Sahara Africa: drivers, impacts and priority policy areas. Renew. Sustain. Energy Rev. 45, 879-901.

Gerssen-Gondelach, S., Wicke, B., Faaij, A., 2015. Assessment of driving factors for yield and productivity developments in crop and cattle production as key to increasing sustainable biomass potentials. Food Energy Secur. 4, 36-75.

Gerssen-Gondelach, S.J., Saygin, D., Wicke, B., Patel, M.K., Faaij, A.P.C., 2014. Competing uses of biomass: assessment and comparison of the performance of biobased heat, power, fuels and materials. Renew. Sustain. Energy Rev. 40, 964-998.

Hoogwijk, M., Faaij, A., De Vries, B., Turkenburg, W., 2009. Exploration of regional and global cost-supply curves of biomass energy from short-rotation crops at abandoned cropland and rest land under four IPCC SRES land-use scenarios. Biomass Bioenergy $33,26-43$.

Hoogwijk, M., Faaij, A., Eickhout, B., Devries, B., Turkenburg, W., 2005. Potential of biomass energy out to 2100 , for four IPCC SRES land-use scenarios. Biomass Bioenergy 29, 225-257.

Hoogwijk, M., Faaij, A., Van Den Broek, R., Berndes, G., Gielen, D., Turkenburg, W., 2003. Exploration of the ranges of the global potential of biomass for energy. Biomass Bioenergy 25, 119-133.

IEA, 2017a. Key World Energy Statistics. International Energy Agency., Paris, France.

IEA, 2017b. Technology Roadmap: Delivering Sustainable Bioenergy. International en ergy Agency., Paris, France.

Kemper, J., 2015. Biomass and carbon dioxide capture and storage: a review. Int. J. Greenh. Gas Control. 40, 401-430.

Klein, D., Luderer, G., Kriegler, E., Strefler, J., Bauer, N., Leimbach, M., Popp, A., Dietrich, J.P., Humpenöder, F., Lotze-Campen, H., Edenhofer, O., 2014. The value of bioenergy in low stabilization scenarios: an assessment using REMIND-MAgPIE. Clim. Change 123, 705-718.

Kriegler, E., O’neill, B.C., Hallegatte, S., Kram, T., Lempert, R.J., Moss, R.H., Wilbanks, T., 2012. The need for and use of socio-economic scenarios for climate change analysis: new approach based on shared socio-economic pathways. Glob. Environ. Chang. Part A $22,807-822$.

Kriegler, E., Weyant, J.P., Blanford, G.J., Krey, V., Clarke, L., Edmonds, J., Fawcett, A., Luderer, G., Riahi, K., Richels, R., Rose, S., Tavoni, M., Van Vuuren, D.P., 2014. The role of technology for achieving climate policy objectives: overview of the EMF27 study on global technology and climate policy strategies. Clim. Change 123, $353-367$.

Lucas, P.L., Van Vuuren, D.P., Olivier, J.G.J., Den Elzen, M.G.J., 2007. Long-term reduction potential of non-CO2 greenhouse gases. Environ. Sci. Policy 10, 85-103.

Luderer, G., Krey, V., Calvin, K., Merrick, J., Mima, S., Pietzcker, R., Van Vliet, J., Wada, K., 2014. The role of renewable energy in climate stabilization: results from the EMF27 scenarios. Clim. Change 123, 427-441.

Matzenberger, J., Kranzl, L., Tromborg, E., Junginger, M., Daioglou, V., Sheng Goh, C., Keramidas, K., 2015. Future perspectives of international bioenergy trade. Renew. Sustain. Energy Rev. 43, 926-941.

Möllersten, K., Yan, J., R. Moreira, J., 2003. Potential market niches for biomass energy with $\mathrm{CO} 2$ capture and storage-opportunities for energy supply with negative $\mathrm{CO} 2$ emissions. Biomass Bioenergy 25, 273-285.

Moreira, J.R., Romeiro, V., Fuss, S., Kraxner, F., Pacca, S.A., 2016. BECCS potential in Brazil: achieving negative emissions in ethanol and electricity production based on sugar cane bagasse and other residues. Appl. Energy 179, 55-63.

Muratori, M., Kheshgi, H., Mignone, B., Clarke, L., Mcjeon, H., Edmonds, J., 2017. Carbon capture and storage across fuels and sectors in energy system transformation pathways. Int. J. Greenh. Gas Control. 57, 34-41.

Nakicenovic, N., Alcamo, J., Davis, G., De Vries, B., Fenham, J., Gaffin, S., Gregory, K., Grübler, A., Jung, T.Y., Kram, T., La Rovere, E.L., Michaelis, L., Mori, S., Morita, T., Pepper, W., Pitcher, H., Price, L., Riahi, K., Roehrl, A., Rogner, H., Sankovski, A., Schlesinger, M., Shukla, P.R., Smith, S., Swart, R., Van Rooijen, S., Victor, N., Dadi, Z., 2000. Special Report on Emissions Scenarios. Intergovernmental Panel on Climate Change., Cambridge, United Kingdom.

O'neill, B.C., Kriegler, E., Ebi, K.L., Kemp-Benedict, E., Riahi, K., Rothman, D.S., Van 
Ruijven, B.J., Van Vuuren, D.P., Birkmann, J., Kok, K., Levy, M., Solecki, W., 2017. The roads ahead: narratives for shared socioeconomic pathways describing world futures in the 21st century. Glob. Environ. Chang. Part A 42, 169-180.

Overmars, K.P., Stehfest, E., Tabeau, A., Van Meijl, H., Beltrán, A.M., Kram, T., 2014. Estimating the opportunity costs of reducing carbon dioxide emissions via avoided deforestation, using integrated assessment modelling. Land Use Policy 41, 45-60.

Plevin, R.J., Beckman, J., Golub, A.A., Witcover, J., O’hare, M., 2015. Carbon accounting and economic model uncertainty of emissions from biofuels-induced land use change. Environ. Sci. Technol. 49, 2656-2664.

Popp, A., Calvin, K., Fujimori, S., Havlik, P., Humpenöder, F., Stehfest, E., Bodirsky, B.L., Dietrich, J.P., Doelmann, J.C., Gusti, M., Hasegawa, T., Kyle, P., Obersteiner, M., Tabeau, A., Takahashi, K., Valin, H., Waldhoff, S., Weindl, I., Wise, M., Kriegler, E., Lotze-Campen, H., Fricko, O., Riahi, K., Vuuren, D.P.V., 2017. Land-use futures in the shared socio-economic pathways. Glob. Environ. Chang. Part A 42, 331-345.

Popp, A., Humpenöder, F., Weindl, I., Bodirsky, B.L., Bonsch, M., Lotze-Campen, H., Müller, C., Biewald, A., Rolinski, S., Stevanovic, M., Dietrich, J.P., 2014. Land-use protection for climate change mitigation. Nat. Clim. Chang. 4, 1095-1098.

Riahi, K., Van Vuuren, D.P., Kriegler, E., Edmonds, J., O'neill, B.C., Fujimori, S., Bauer, N., Calvin, K., Dellink, R., Fricko, O., Lutz, W., Popp, A., Cuaresma, J.C., Kc, S., Leimbach, M., Jiang, L., Kram, T., Rao, S., Emmerling, J., Ebi, K., Hasegawa, T., Havlik, P., Humpenöder, F., Da Silva, L.A., Smith, S., Stehfest, E., Bosetti, V., Eom, J., Gernaat, D., Masui, T., Rogelj, J., Strefler, J., Drouet, L., Krey, V., Luderer, G., Harmsen, M., Takahashi, K., Baumstark, L., Doelman, J.C., Kainuma, M., Klimont, Z., Marangoni, G., Lotze-Campen, H., Obersteiner, M., Tabeau, A., Tavoni, M., 2017. The shared Socioeconomic Pathways and their energy, land use, and greenhouse gas emissions implications: an overview. Glob. Environ. Chang. Part A 42, 153-168.

Rogelj, J., Popp, A., Calvin, K., Luderer, G., Emmerling, J., Gernaat, D., Fujimori, S. Strefler, J., Hasegawa, T., Marangoni, G., Krey, V., Kriegler, E., Riahi, K., Van Vuuren, D., Doelman, J.C., Drouet, L., Edmonds, J., Fricko, O., Harmsen, M., Havlik, P., Humpenöder, F., Stehfest, E., Tavoni, M., 2018. Scenarios towards limiting global mean temperature increase below $1.5^{\circ} \mathrm{C}$. Nat. Clim. Chang. 8, 325-332.

Rose, S., Kriegler, E., Bibas, R., Calvin, K., Popp, A., Van Vuuren, D.P., Weyant, J.P., 2014. Bioenergy in energy transformation and climate management. Clim. Change 123, 477-493.

Searchinger, T., Heimlich, R., Houghton, R.A., Dong, F., Elobeid, A., Fabiosa, J., Tokgoz, S., Hayes, D., Yu, T.H., 2008. Use of US croplands for biofuels increases greenhouse gases through emissions from land-use change. Science 319, 1238-1240.

Searchinger, T.D., Estes, L., Thornton, P.K., Beringer, T., Notenbaert, A., Rubenstein, D. Heimlich, R., Licker, R., Herrero, M., 2015. High carbon and biodiversity costs from converting Africa's wet savannahs to cropland. Nat. Clim. Chang. 5, 481-486.

Slade, R., Bauen, A., Gross, R., 2014. Global bioenergy resources. Nat. Clim. Chang. 4, 99-105.

Smeets, E., Faaij, A., Lewandowski, I., Turkenburg, W., 2007. A bottom-up assessment and review of global bio-energy potentials to 2050. Prog. Energy Combust. Sci. 33, 56-106.

Stehfest, E., Van Vuuren, D., Kram, T., Bouwman, A.F., Alkemade, R., Bakkenes, M., Biemans, H., Bouwman, A.F., Den Elzen, M., Janse, J., Lucas, P.L., Van Minnen, J.G., Müller, C., Prins, A.G., 2014. Integrated Assessment of Global Environmental Change With IMAGE 3.0 - Model Description and Applications, the Hague, the Netherlands, PBL Netherlandds Environmental Assessment Agency.

Tagomori, I.S., Carvalho, F.M., Da Silva, F.T., Merschmann, P.R.D.C., Rochedo, P.R., Szklo, A., Schaeffer, R., 2018. Designing an optimum carbon capture and transportation network by integrating ethanol distilleries with fossil-fuel processing plants in Brazil. Int. J. Greenh. Gas Control. 68, 112-127.

Van Vuuren, D.P., Den Elzen, M.G.J., Lucas, P.L., Eickhout, B., Strengers, B.J., Van Ruijven, B., Wonink, S., Van Houdt, R., 2007. Stabilizing greenhouse gas concentrations at low levels: an assessment of reduction strategies and costs. Clim. Change 81, 119-159.

Van Vuuren, D.P., Edmonds, J., Kainuma, M., Riahi, K., Thomson, A., Hibbard, K., Hurtt, G.C., Kram, T., Krey, V., Lamarque, J.-F., Masui, T., Meinshausen, M., Nakicenovic, N., Smith, S.J., Rose, S.K., 2011. The representative concentration pathways: an overview. Clim. Change 109, 5-31.

Van Vuuren, D.P., Stehfest, E., Gernaat, D.E.H.J., Doelman, J.C., Van Den Berg, M., Harmsen, M., De Boer, H.S., Bouwman, L.F., Daioglou, V., Edelenbosch, O.Y., Girod, B., Kram, T., Lassaletta, L., Lucas, P.L., Van Meijl, H., Müller, C., Van Ruijven, B.J., Van Der Sluis, S., Tabeau, A., 2017. Energy, land-use and greenhouse gas emissions trajectories under a green growth paradigm. Glob. Environ. Chang. Part A 42, 237-250.

WBA, 2016. WBA Global Bioenergy Statistics 216. World Bioenergy Association., Stockholm, Sweden.

Wicke, B., Verweij, P., Van Meijl, H., Van Vuuren, D., Faaij, A., 2012. Indirect land use change: review of existing models and strategies for mitigation. Biofuels $3,87-100$. 